\title{
Unechtes und Zweifelhaftes unter den Deklamationen des Libanios - die statistische Evidenz
}

\author{
DIETMAR NAJOCK
}

\section{Einleitung}

\subsection{Vorbemerkungen}

Die Begriffe „unecht“ und „zweifelhaft“ sind hier, sofern der Kontext nicht auf etwas anderes hinweist, auf die entsprechende Einstufung der einzelnen Werke in dem RE-Artikel von Foerster/Münscher bezogen, ${ }^{1}$ ebenso wie in den Tabulae unserer Libanios-Konkordanz. ${ }^{2}$ Wie dort werden auch hier die Titel der in diesem Sinne unechten Werke in eckige Klammern gesetzt, etwa [Decl.18], und die der zweifelhaften in runde Klammern, z.B. (Decl.15). Diese Einstufung weicht im übrigen von der älteren in Foersters Libanios-Ausgabe ab: ${ }^{3}$ Dort erscheint (Decl.6) als echt, aber Decl.2 als zweifelhaft. ${ }^{4}$ Insgesamt gelten nach Foerster/Münscher 13 der 51 Deklamationen als unecht oder zweifelhaft: (Decl.6), (Decl.15), (Decl.16), [Decl.18], [Decl.20], [Decl.23], [Decl.29], [Decl.34], [Decl.40], [Decl.43], [Decl.45], [Decl.49] und [Decl.51]. ${ }^{5}$

Die Gründe für Foersters Entscheidungen sind verschiedener Natur, es sind erstens negative Gesamturteile der höheren Literatur- und Stilkritik - Urteile, die ihrer Natur nach schwer zu belegen sind und manchmal auch subjektiv gefärbt

1 R. Foerster/K. Münscher, Libanios, in: RE XII, Stuttgart 1925, Sp. 2485-2551.

2 G. Fatouros/T. Krischer/D. Najock, Concordantiae in Libanium, Pars Tertia, Declamationes, Progymnasmata, Argumenta orationum Demosthenicarum, 5 Bde., Hildesheim 2000. Dazu Pars Quarta, Tabulae, Volumen I, Tabulae in Epistulas et Orationes, Hildesheim 1996, Volumen II, Pars 1, Tabulae in Declamationes et Progymnasmata, und Volumen II, Pars 2, Tabulae in Corpus Libanianum, beide Hildesheim 2003.

3 Libanius, Opera, ed. R. Foerster, Leipzig 1903-1922.

4 In der Praefatio zu [Decl.20], Libanius VI, 291, stellt Foerster Decl.2 in dieser Hinsicht mit (Decl.15), (Decl.16) und eben [Decl.20] gleich.

5 B. Schouler, La tradition hellénique chez Libanios, Paris 1984, I 27-34, gibt eine tabellarische Übersicht über Themen und Gattungen der Deklamationen, in welcher er auch, gestützt auf Foersters Ausgabe, mit doppelten und einfachen Fragezeichen zwei Stufen von Zweifeln an der Authentizität notiert. Starken Zweifeln unterlägen demnach bei Foerster [Decl.18], [Decl.34], [Decl.40], [Decl.43], [Decl.45], [Decl.49] und [Decl.51], weniger starken Zweifeln Decl.2, (Decl.15), (Decl.16), [Decl.20], [Decl.23] und [Decl.29]. 
sein mögen, die aber, da Foerster das Corpus Libanianum wie wohl kein zweiter gekannt hat, von größtem Wert sind. Hinzu kommen zweitens konkrete, d.h. mit Einzelstellen belegte Anstöße sprachlicher Art, ${ }^{6}$ drittens inhaltliche Fehler und viertens Wörter, die Foerster dem Libanios abspricht. Was den letztgenannten Punkt betrifft, muß allerdings angemerkt werden, daß Wörter, die nur in einer vermutlich unechten Deklamation vorkommen, sonst aber bei Libanios nicht belegt sind, noch keinen Anlaß zu Zweifeln geben müssen, denn die von Libanios genau einmal verwendeten Wörter sind sehr zahlreich, sie machen fast ein Drittel des gesamten Wortbestandes im Corpus Libanianum aus. ${ }^{7}$ Überschneidungen von Foersters Argumenten und den hier statistisch untersuchten Merkmalen gibt es im übrigen kaum. ${ }^{8}$

Die Statistik kommt zu Wahrscheinlichkeitsaussagen, nicht zu absoluter Sicherheit. So ist auch das Wort „Evidenz“ im Titel dieses Aufsatzes nicht im Sinne völliger Klarheit, die nicht mehr begründet werden müßte, zu verstehen, sondern im Sinne zusätzlichen Lichtes, das die Sprachstatistik auf die Echtheitsfrage zu werfen vermag, und zwar aufgrund des derzeit in den Tabulae vorliegenden statistischen Materials. In den Tabulae nachzuschlagen, wird für den Leser dieses Aufsatzes sehr nützlich sein, teils wegen der etwas ausführlicheren Erläuterungen in den dortigen Einleitungen, teils um die hier herangezogenen Daten in ihren Gesamtrahmen einordnen und überprüfen zu können, vor allem aber um die baumartig strukturierten Diagramme, die die Werke nach Ähnlichkeit in Grüppchen und Gruppen zusammenfassen, anschaulich vor Augen zu haben.

\subsection{Die statistisch erfaßten Merkmale}

Die hier untersuchten Merkmale liegen so weit an der Oberfläche der Texte, daß sie ohne Formbestimmung und ohne Syntaxanalyse mit Computerprogrammen erfaßt werden konnten. Dennoch bleibt ihre stilistische Bedeutung erkennbar. Ihrer Struktur nach sind sie von zweierlei Art, zum einen liefern sie für ein bestimmtes Werk nur eine einzige Zahl, etwa die mittlere Satzlänge, zum anderen liefern sie eine ganze Reihe von Zahlen, eine Häufigkeitsverteilung, z.B. die Häu-

6 Verbformen, Gebrauch der Modi und Tempora, Wortstellung.

7 Im Gesamtkorpus kommen 3254 Lemmata genau einmal vor, 1370 genau zweimal, 811 genau dreimal u.s.w., vgl. Tabulae 2.2, 817f., „Verteilung der Worthäufigkeiten im Gesamtkorpus (mit Brieftiteln)“", wo die Eigennamen eingeschlossen sind. Nach Tabulae 2.2, 574, umfaßt das Gesamtkorpus 10966 Lemmata (mit Eigennamen und Brieftiteln), also gut das Dreifache der genau einmal vorkommenden Wörter.

$8 \mathrm{Zu}$ den angeführten Arten von Argumenten, die alle aus den Deklamationen selbst gewonnen sind, kommen im RE-Artikel von Foerster/Münscher gelegentlich noch überlieferungsgeschichtliche Indizien. 
figkeiten der Wortarten. Die Merkmale der ersten Art führen zu eindimensionalen Skalierungen, die der zweiten Art, ihrer Natur nach mehrdimensionale Größen, erfordern Verteilungsvergleiche wie den Chi-Quadrat-Test und führen damit zu andersartigen Ergebnissen, besonders zu einer Wiedergabe der eigentlich mehrdimensionalen Gruppenbildung in einem baumartig strukturierten Diagramm, auch Dendrogramm genannt.

Für die eindimensionalen Skalierungen sollen hier hauptsächlich fünf Merkmale herangezogen werden, Vokabularreichtum, mittlere Wortlänge, Hiatrate, mittlere Satzlänge und Anteil der Fragen: (a) Der Vokabularreichtum einer Deklamation wird als z-Wert gemessen, genauer als normierte Abweichung von der statistischen Erwartung. ${ }^{9}$ Die z-Werte hängen nicht mehr von der Textlänge ab und folgen in guter Näherung der Standardnormalverteilung. ${ }^{10}$ Sie sind direkt miteinander vergleichbar, und ihre Signifikanz kann anhand der kritischen Schranken der genannten Verteilung beurteilt werden. ${ }^{11}$ Der Vokabularreichtum ist wesentlich durch den aktiven Wortschatz und entsprechende Aktivierungsleistungen bestimmt. Streben nach Variation und Vermeiden von Wiederholungen heben ihn an. (b) Die mittlere Wortlänge wird in der Anzahl von Buchstaben gemessen und mit zwei Nachkommastellen angegeben. Berechnet ist sie als Quotient aus der Anzahl der Buchstaben und der Anzahl der Wörter einer Deklamation. ${ }^{12}$ Die mittlere Wortlänge steht unter dem Einfluß der Verwendung von sogenannten kleinen Wörtern einerseits und von Komposita und langen Endungen andererseits. (c) Die Hiatrate gibt an, wieviel Prozent der Wortfugen einen Hiat aufweisen. Im Normalfall werden dabei nur einfache Wortfugen betrachtet, d.h. solche ohne Interpunktion. (d) Die mittlere Satzlänge wird in der Anzahl von Wörtern gemessen und mit einer Nachkommastelle angegeben. Berechnet ist sie als Quotient aus der Anzahl der Wörter und der Anzahl der Sätze einer Deklamation. ${ }^{13}$ Die mittlere Satzlänge ist ein vereinfachtes Maß für die Komplexität des Satzbaus; als vereinfachtes $\mathrm{Ma} ß \mathrm{mu} ß$ sie gelten, weil z.B. Unterordnung und Beiordnung nicht unterschieden werden. (e) Der Anteil der Fragen gibt an, wieviel Prozent der Sätze Fragesätze sind. Diese sind in der Regel als rhetorische Fragen anzusehen.

$\mathrm{Zu}$ diesen fünf systematisch ausgewerteten Merkmalen kommen noch zwei eher beiläufig verwendete, die mittlere Anzahl der Abschnitte pro Satz und die

9 Zur Definition der z-Werte vgl. Abschnitt 1.4. Die für die Berechnung von Erwartungswert und Standardabweichung nötigen Formeln sind den Tabulae 2.1, XX, zu entnehmen.

10 Die Normalverteilung wird durch die sogenannte Gaußsche Glockenkurve beschrieben. In ihrer Standardversion liegt sie symmetrisch um Null (den Erwartungswert), mit einer mittleren quadratischen Abweichung von 1.0.

$11 \mathrm{Zu}$ diesen kritischen Schranken vgl. Abschnitt 1.4 unten.

12 Iota subscriptum ist dabei nicht mitgezählt worden.

13 Satzenden sind dabei durch Punkt, Kolon und Semikolon definiert. 
Dichte der Erstbelege: (f) Die mittlere Anzahl der Abschnitte pro Satz ist der Quotient aus der Anzahl der Satzabschnitte und der Anzahl der Sätze einer Deklamation, angegeben mit zwei Nachkommastellen. Dabei gilt als Satzabschnitt, was durch Komma oder Satzende begrenzt ist. Bestimmt ist diese Größe durch asyndetische Reihung, Antithese und Nebensatzbildung. (g) Die Dichte der Erstbelege gibt an, wieviel Promille der Textmasse einer Deklamation von Wörtern eingenommen werden, die vor Libanios nicht belegt sind. Da Libanios sich weitgehend an klassischen Vorbildern orientiert hat, kann eine hohe Erstbelegdichte gegen die Authentizität eines Werks sprechen.

Als mehrdimensionale Merkmale werden die Verteilungen von häufigen Funktionswörtern, häufigen allgemeineren Inhaltswörtern, Wortarten und Buchstaben herangezogen: (h) $\mathrm{Zu}$ den Funktionswörtern zählen Präpositionen, Konjunktionen, Partikeln, Negationen und Interjektionen, ferner Pronomina und korrelative Pronominaladjektive. Sie gelten als häufig bei mindestens 70 Vorkommen im gemeinsamen Korpus von Deklamationen und Progymnasmata. (i) Häufige allgemeinere Inhaltswörter sind solche, die nicht zu den Funktionswörtern zählen, aber auch nicht zu eng an bestimmte Inhalte gebunden sein sollten, etwa Orts-, Zeit- und Modaladverbien, Hilfsverben und unspezifische Verben wie $\pi$ oté $\omega$, außerdem Adjektive des Maßes und der allgemeinen Bewertung, ebenfalls bei mindestens 70 Vorkommen in Deklamationen und Progymnasmata. (j) Bei den Wortarten sind zehn Klassen unterschieden, Eigennamen, Adjektive, Adverbien, Interjektionen, beiordnende Konjunktionen, unterordnende Konjunktionen, Präpositionen, Pronomina, Substantive und Verben. ${ }^{14}(\mathrm{k})$ Die Buchstaben sind die des griechischen Alphabets. ${ }^{15}$ Die Buchstabenverteilung eines Werkes ist durch seinen Wortformenbestand bestimmt. ${ }^{16}$ Sie nimmt für verschiedene Autoren und z.T. sogar für verschiedene Werke eines Autors offenbar ziemlich charakteristische Ausprägungen an. G. R. Ledger hat am Beispiel einiger klassischer attischer Autoren gezeigt, daß Textabschnitte von je 1000 Wörtern bei der automatischen Klassifizierung nach der Ähnlichkeit ihrer Buchstabenverteilungen erstaunlich oft dem richtigen Autor (und Werk) zugeordnet werden. ${ }^{17}$

14 Numeralia sind als Zahladjektive bzw. Zahladverbien den entsprechenden Klassen zugewiesen worden, ebenso Negationen und Partikeln als Schattierungsadverbien.

15 Iota subscriptum ist nicht mitgezählt, und beide Formen des Sigma sind als ein und derselbe Buchstabe behandelt worden.

16 Der Wortformenbestand kann seinerseits durch Tendenzen der lautlichen Gestaltung mitgeprägt sein.

17 G. R. Ledger, A New Approach to Stylometry, in: Association for Literary and Linguistic Computing Bulletin 13,3 (1985) 67-72. 


\subsection{Zur Aussagekraft der Merkmale}

Fast alle genannten Merkmale habe ich schon im Briefkorpus und im Redenkorpus des Libanios untersucht. ${ }^{18}$ Um ein Bild von ihrer Aussagekraft zu vermitteln, seien hier die Hauptergebnisse dieser Untersuchung zusammengefaßt: (a) Der in einen z-Wert umgerechnete Vokabularumfang (die normierte Abweichung von seiner statistischen Erwartung) ist in den späten Briefen deutlich niedriger als in denen der Blütezeit des Libanios. Auch unter den Redengruppen gibt es große Unterschiede, doch so, daß sie im allgemeinen ein reicheres Vokabular haben als die gleichzeitigen Briefe. ${ }^{19}$ (b) Die mittlere Wortlänge vermag die 17 Jahresgruppen der Briefe fast sauber von den 14 Redengruppen zu trennen. Nur die Gruppe der religiösen Reden liegt, mit geringen Wortlängen, im Bereich der Briefgruppen. ${ }^{20}$ (c) Die Hiatrate ist in Briefen und Reden nicht untersucht worden. (d) In der mittleren Satzlänge liegen die späten Briefe so weit über denen der Blütezeit, daß sie einige Redengruppen erreichen. Abgehoben bleiben die epideiktischen Reden. ${ }^{21}$ (e) Im Anteil der Fragen liegen die meisten Redengruppen weit über dem eng umgrenzten Bereich der Briefgruppen, die epideiktischen Reden und Or.39 aber nur knapp, Autobiographie und religiöse Reden schließlich liegen ganz im Bereich der Briefe. Es ist leicht einzusehen, daß die beiden letztgenannten Redentypen nicht viel Raum für rhetorische Fragen bieten. Unterschiede unter den Redengruppen überlagern hier also den Unterschied von Reden und Briefen. (f) Die mittlere Anzahl der Abschnitte pro Satz trennt die Redengruppen fast sauber von den Jahresgruppen der Briefe. Einzige Ausnahme ist die Gruppe der an hohe Beamte gerichteten Angriffsreden, die mit dem niedrigen Mittel von 2.29 noch im Bereich der Briefe liegt. ${ }^{22}$ (g) Die Dichte der Erstbelege in Briefen und Reden ist bisher nicht untersucht worden. Es sei hier angemerkt, daß sie für das Briefkorpus 0.05 und für das Redenkorpus 0.10 Promille beträgt. Or.11 enthält zwar 6 Erstbelege, da diese Rede aber sehr lang ist (15081 Wörter), werden auch damit nur 0.40 Promille erreicht. ${ }^{23}$ (h) Die automatische Klassifikation nach

18 D. Najock, Sprachstatistische Untersuchungen zu den Briefen und Reden des Libanios, 2 Bde., Hildesheim 2000. Als Supplement der Concordantiae in Libanium erschienen.

19 Sprachstatistische Untersuchungen 1, 180f.

20 Sprachstatistische Untersuchungen 1, 182.

21 Sprachstatistische Untersuchungen 1, 185.

22 Sprachstatistische Untersuchungen 1, 186.

23 Die Erstbelege im Corpus Libanianum sind gesammelt in Tabulae 2.2, 577, 597f. und 605f., unter „(Lib.)“, „Lib.“ und „[Lib.]“. Die Konkordanz führt dann auf die fraglichen Einzelreden. Der Textumfang dieser Reden findet sich in Tabulae 1, 673f., unter „tlength“. Daraus errechnet man die Erstbelegdichte: Or.28 0.47\%o, Or.21 0.40\%, Or.11 0.40\%, Or.55 0.36\%, Or.63 0.31\%, Or.1 0.28\%, Or.33 0.27\%, Or.46 0.27\%, Or.2 0.26\%, Or.59 0.24\%, Or.64 0.10\%, Or. 18 0.05\%. Alle anderen Reden enthalten keine Erstbelege und kommen auf 0.00\%. Es werden hier also nirgends 0.5 Promille erreicht. 
Funktionswörtern liefert für die Briefe des Libanios eine Anordnung der Jahresgruppen, die nicht nur die späten Briefe sehr deutlich von denen der Blütezeit abgrenzt, sondern auch innerhalb dieser beiden Familien - mit Ausnahme des Jahres 388 - ganz zur Chronologie paßt. In ein Klammersystem übertragen ist es die folgende Anordnung: ${ }^{24}$

$$
\begin{gathered}
\{\{\{355,\{356,357\}\}, 358\},\{\{\{359,360\}, 361\},\{\{362,363\},\{364,365\}\}\}\}, \\
\{\{390,391\},\{388,\{392,393\}\}\} .
\end{gathered}
$$

Bei den Reden zeigt sich hier - wie auch im Falle der allgemeineren Inhaltswörter und der Wortarten - vor allem ein Einfluß des Redentyps. Die gemeinsame Klassifikation der Brief- und Redengruppen nach den allerhäufigsten Wörtern (die fast alle Funktionswörter sind) trennt die Briefgruppen deutlich von den Redengruppen ab. Auch hierbei ist die chronologische Ordnung weitgehend gewahrt. ${ }^{25}$ (i) Bei der automatischen Klassifikation nach allgemeineren Inhaltswörtern werden die Briefgruppen der frühen Jahre (bis 358) etwas stärker abgetrennt als die der Altersjahre, im übrigen aber ergibt sich wiederum bis auf eine Ausnahme, diesmal das Jahr 360, eine ganz zur Chronologie passende Anordnung: ${ }^{26}$

$$
\{\{355,356\},\{357,358\}\},
$$

$$
\{\{\{\{\{359,361\}, 360\}, 362\},\{\{363,364\}, 365\}\},\{\{388,\{390,\{391,392\}\}\}, 393\}\} \text {. }
$$

(j) Die Klassifizierung nach Wortarten trennt die Briefe der Altersjahre noch deutlicher von denen der Blütezeit als die Klassifikation nach Funktionswörtern. Innerhalb der Blütezeit treten hier aber mehrere Verschiebungen gegenüber der korrekten Chronologie zutage: ${ }^{27}$

$$
\begin{gathered}
\{\{\{\{\{356,\{357,\{355,360\}\}\},\{361,\{362,363\}\}\}, 359\}, 358\},\{364,365\}\}, \\
\{\{388,390\},\{\{391,392\}, 393\}\} .
\end{gathered}
$$

Bei der gemeinsamen Klassifikation von Brief- und Redengruppen tritt eine in sich geschlossene Familie von Redengruppen zwischen die ebenfalls in sich geschlossenen Familien der Briefe der Altersjahre und der Blütezeit, wie sie hier angegeben sind. (k) Die gemeinsame Klassifizierung der Brief- und Redengruppen nach den Buchstabenverteilungen faßt die Briefgruppen, deutlich abgetrennt von den Redengruppen, in einer geschlossenen Familie zusammen, deren innere Struktur weitgehend zur chronologischen Ordnung paßt: ${ }^{28}$

$$
\begin{aligned}
\{\{355,\{356,357\}\},\{\{359,\{358,360\}\},\{362,\{\{361,363\},\{364,365\}\}\}\}\}, \\
\{\{388,390\},\{391,\{392,393\}\}\} .
\end{aligned}
$$

Die Klassifikation der Briefgruppen allein liefert dieselbe Struktur.

24 Tabulae 1, 248. Sprachstatistische Untersuchungen 1, 109. Die Zahlen 355 u.s.w. stehen für die in den betreffenden Jahren verfaßten Briefe, die geschweiften Klammern sind als Mengenklammern zu lesen, die diese Jahresgruppen nach Ähnlichkeit zusammenfassen.

25 Tabulae 1, 856. Sprachstatistische Untersuchungen 1, 197. Einzige Ausnahme ist hier die Jahresgruppe 359 .

26 Tabulae 1, 260. Sprachstatistische Untersuchungen 1, 109f.

27 Tabulae 1, 262 und 858. Sprachstatistische Untersuchungen 1, 99f. und 195-197.

28 Tabulae 1, 286 und 860. Sprachstatistische Untersuchungen 1, 83 und 191f. 


\subsection{Die statistischen Methoden}

Häufig ist es sinnvoll, eine gegebene Größe wie den beobachteten Vokabularumfang einer Deklamation oder ihre mittlere Wortlänge zu standardisieren. Dazu wird sie durch Subtraktion ihres Erwartungswertes zunächst um Null zentriert und dann mittels Division durch die Standardabweichung normiert, d.h. auf eine mittlere Abweichung von 1.0 gebracht. ${ }^{29}$ Derartig standardisierte Größen werden als z-Werte bezeichnet. Sie geben die Abweichung von der Erwartung an und folgen dabei meist in guter Näherung der Standardnormalverteilung, so daß sie direkt miteinander wie auch mit den kritischen Schranken dieser Verteilung verglichen werden können: Als schwach signifikant gelten danach z-Werte, die über 1.96 oder unter -1.96 liegen, als signifikant solche über 2.58 oder unter -2.58, als stark signifikant solche über 3.29 oder unter -3.29. Schwach signifikante Abweichungen von der Erwartung können sich in 5\% aller Fälle auch rein zufällig ergeben, signifikante in nur $1 \%$ und stark signifikante in nur $0.1 \%$ aller Fälle. Speziell in diesem Aufsatz werde ich z-Werte ab 4.5 bzw. bis zu -4.5 als hoch signifikant bezeichnen und solche ab 7.0 bzw. bis zu -7.0 als extrem signifikant. In diesem Sinne hoch signifikante Abweichungen ergeben sich nur in ca. $0.001 \%$ aller Fälle zufällig, extrem signifikante in weniger als $0.000000001 \%$ aller Fälle. ${ }^{30}$

Mit dem Chi-Quadrat-Test können zwei Verteilungen verglichen werden, es kann aber auch eine größere Tabelle bzw. Kontingenztafel auf Homogenität, d.h. auf prinzipielle Gleichheit der in ihren Spalten oder Zeilen enthaltenen Verteilungen, überprüft werden. Der Test liefert einen Wert, der um so höher ist, je verschiedener die verglichenen Verteilungen sind oder je inhomogener die überprüfte Tabelle ist. Beim Test auf Homogenität liefert jede Tabellenzelle - etwa ein bestimmtes Funktionswort (Zeile) in einer bestimmten Deklamation (Spalte) ihren Beitrag als Summand des resultierenden Chi-Quadrat-Wertes. Diese Beiträge zeigen schon, wo im einzelnen die besonderen Abweichungen vom Korpusdurchschnitt liegen, sie können aber nach einer Formel von Haberman in regelrechte z-Werte umgerechnet werden, die in diesem Spezialfall Residuen heißen. ${ }^{31}$ Die Tabulae enthalten die Residuentabellen für alle hier behandelten Verteilungen. ${ }^{32}$ Außerdem ist es möglich, den aus einem Verteilungsvergleich bzw. Chi-

29 Für den Erwartungswert kann als Schätzung oft das Korpusmittel eingesetzt werden, für die Standardabweichung unter Umständen die Quadratwurzel des Erwartungswertes, manchmal sind aber für Erwartungswert bzw. Standardabweichung auch spezielle Formeln erforderlich, so insbesondere beim Vokabularumfang.

30 In Tabulae 2.1, XVIII, und Tabulae 2.2, XVIII, haben die für die kritischen Schranken 5.33, 5.73 und 6.11 angegebenen Wahrscheinlichkeiten nach dem Komma je eine Null zu wenig. Richtig in Najock, Sprachstatistische Untersuchungen 1,14.

31 B. S. Everitt, The Analysis of Contigency Tables, London 1977, 46-48.

32 Tabulae 2.1, 297ff. Residuen der Funktionswörter, 323ff. Residuen der allgemeineren Inhalts- 
Quadrat-Anpassungstest gewonnenen Chi-Quadrat-Wert nach einer Formel von Zevero/Zelen in einen $z$-Wert umzurechnen. ${ }^{33}$ So läßt sich einfach beurteilen, in welchem Maße z.B. die Verteilung der Funktionswörter in einer bestimmten Deklamation von der Verteilung im Gesamtkorpus der Deklamationen abweicht. Damit ist eine Art Individualitätsgrad der Deklamation gegeben.

Die automatische Klassifikation führt zu einer vielfach verschachtelten Gruppierung der Deklamationen nach Ähnlichkeit, dargestellt als Dendrogramm. Die Klassifizierung selbst besteht in sukzessiven Zusammenfassungen der jeweils beiden ähnlichsten Deklamationsgruppen. ${ }^{34}$ Anfangs bildet jede Deklamation eine eigene Gruppe, am Ende sind alle in der Gesamtgruppe vereinigt. Im Dendrogramm stehen die Einzeldeklamationen an den Zweigenden, die Gesamtgruppe an der Baumwurzel. Was von der Wurzel ausgehend als Verzweigungspunkt erscheint, entspricht im Entstehungsprozess des Diagramms einer Zusammenfassung zweier Gruppen. Die Ähnlichkeit, die zu einer Zusammenfassung führt, bestimmt die Länge der vom Zusammenfassungs- bzw. Verzweigungspunkt ausgehenden Zweige. ${ }^{35}$ So läßt sich am Dendrogramm gut ablesen, wie isoliert bestimmte Deklamationen oder Deklamationsgruppen sind, insbesondere auch, ob unechte und zweifelhafte Deklamationen abseits der echten stehen.

Tatsächlich zeigt sich, daß als unecht oder zweifelhaft eingestufte Deklamationen in den Dendrogrammen wie auch in den eindimensionalen Skalierungen sehr oft Außenseiterpositionen einnehmen. Allerdings geraten gelegentlich auch echte Werke in solche Positionen. Sie überschreiten dann den Rahmen zufälliger Schwankungen und könnten als Ausnahmen oder Ausreißer im statistischen Sinne bezeichnet werden, es wird aber wichtig sein, derartige Abweichungen, die als systematisch anzusehen sind, nach Möglichkeit mit den jeweiligen Umständen zu erklären, etwa mit dem Inhalt, der literarischen Gattung oder einer besonderen Darstellungsabsicht des Libanios. Zumindest wo dies nicht möglich ist, dürften sich, eben aufgrund einer vorwiegend bei unechten Werken anzutreffenden Position, doch Zweifel an der Authentizität ergeben. ${ }^{36}$ Ausnahmen aber müssen Ausnahmen bleiben: Es ist daher vor allem darauf zu sehen, ob ein Werk in nicht nur

wörter, 346f. Residuen der Wortarten, 351f. Residuen der Buchstaben.

33 L. Sachs, Statistische Auswertungsmethoden, Berlin (u.a.) ${ }^{3} 1972,114$.

34 Die Ähnlichkeit zweier Deklamationen habe ich über den Chi-Quadrat-Wert aus dem Vergleich zweier Verteilungen ermittelt. Die Ähnlichkeit zweier Gruppen ist in dem gewählten Verfahren - der average-linkage pair-group method - definiert als die durchschnittliche Ähnlichkeit derjenigen Deklamationspaare, von denen eine Deklamation in der einen und die andere in der anderen Gruppe liegt. Dieses Verfahren hat sich vielfach bewährt, vgl. dazu R. M. Cormack, A review of classification, in: Journal of the Royal Statistical Society, Ser. A 134 (1971) 321-367.

35 Die in den Zweiglängen enthaltene Information geht verloren, wenn man ein Dendrogramm in ein Klammersystem überträgt.

36 Auch ohne Vorannahmen zur Echtheit bestimmter Deklamationen müßten Extrempositionen und Außenseiterverhalten zum Kriterium für Zweifel an der Authentizität gewählt werden. 
einem, sondern in mehreren, möglichst voneinander unabhängigen Merkmalen Außenseiterpositionen einnimmt und von den echten Werken abweicht. ${ }^{37}$ Jedoch ist, wie man sehen wird, auch mit diesem Kriterium keine eindeutige Abgrenzung authentischer und nicht authentischer Werke möglich. Was die statistische Untersuchung leisten kann, ist nicht mehr, aber auch nicht weniger, als eine Verdichtung der Indizien.

\section{Skalierungen}

\subsection{Vokabularumfang}

Reichtum bzw. Armut des Vokabulars werden hier in z-Werten gemessen, die vom Textumfang unabhängig sind. Die signifikantesten Abweichungen von der statistischen Erwartung sind im negativen Bereich die folgenden: ${ }^{38}$

[Decl.49] z=-15.22, (Decl.6) z=-14.43, [Decl.40] z=-12.46, Decl.44 z=-12.12, Decl.38 z=-11.57, [Decl.43] z=-11.12, Decl.47 z=-11.06. Das reichste Vokabular dagegen haben diese: [Decl.51] z=2.60, Decl.26 z=2.19, Decl.33 z=1.20, Decl.28 $\mathrm{z}=-0.41$, Decl.30 $\mathrm{z}=-0.98$. Insgesamt ist eine Verschiebung in den negativen Bereich zu konstatieren, die immer wieder zu beobachten ist, wenn Einzeltexte eines Korpus mit dem Gesamtkorpus verglichen werden - nicht wegen unterschiedlicher Textlängen, sondern weil ein Korpus thematisch und manchmal auch hinsichtlich der literarischen Gattung mehr oder weniger breit gefächert vorliegt, während ein Einzelwerk nur einer Gattung angehört und in der Regel auch nur einem Thema gewidmet ist. Das führt automatisch zu einer größeren Vielfalt im Wortschatz des Korpus, und zwar, um dies noch einmal zu betonen, unabhängig von der Textlänge. Um so auffälliger ist, daß einige Deklamationen dicht beim Korpuswert 0.00 liegen $^{39}$ bzw. ihn sogar übertreffen, nämlich die echten Deklamationen Decl.26, Decl.33, Decl.28 und Decl.30 sowie die unechte [Decl.51], letztere sogar mit dem höchsten Wert. Die Sonderposition von [Decl.51] ist wohl teilweise damit zu erklären, daß diese Deklamation die einzige Monodie des Deklamationskorpus ist, zugleich die einzige epideiktische Deklamation der etholo-

37 Die hier herangezogenen sieben eindimensionalen und vier mehrdimensionalen Merkmale scheinen ziemlich unabhängig voneinander zu sein. Der Anteil der Fragen beeinflußt aber de facto die mittlere Satzlänge (da Fragen im Durchschnitt kürzer sind), und die Satzlänge ist deutlich mit der Anzahl der Abschnitte pro Satz verbunden. Dennoch liegt auch in diesen Fällen keine strenge Korrelation vor.

38 Tabulae 2.1, 370, unter, ,z(Vu)“.

39 Die Abweichung des Korpus von der statistischen Erwartung bzw. von sich selbst muß natürlich den Wert 0.00 haben. 
gischen Gruppe. ${ }^{40}$ Klammert man [Decl.51] aufgrund des besonderen literarischen Genus aus, so sind die vier Deklamationen mit dem reichsten Vokabular echt, die drei mit dem ärmsten aber unecht bzw. angezweifelt. Das stärkt die Annahme der Unechtheit von [Decl.49], (Decl.6) und [Decl.40].

\subsection{Mittlere Wortlänge}

Die mittlere Wortlänge ist nicht nur in absoluten Werten gegeben, sondern auch umgerechnet $\mathrm{zu}$ z-Werten, die mit den kritischen Schranken der Standardnormalverteilung verglichen werden können. ${ }^{41}$ Danach heben sich am auffälligsten, d.h. mit den höchsten Signifikanzen, einige wenige Deklamationen mit besonders großer Wortlänge heraus: [Decl.49] z=12.95, [Decl.18] z=8.21, Decl.25 $\mathrm{z}=8.16,[$ Decl.20] $\mathrm{z}=7.98$. In etwas größerem Abstand folgen Decl.24 mit z=5.83 sowie [Decl.45] und Decl.12 mit z=4.32. Die Häufung unechter Deklamationen im positiven Extrembereich ist deutlich, doch eine klare Abgrenzung zu den echten ist durch Decl.25 erschwert. Man wird, wenn man an der Echtheit von Decl.25 (und Decl.24) festhalten will, kaum mehr folgern können, als daß die auffallend große Wortlänge für die Unechtheit von [Decl. 49] spricht, mit Einschränkung auch für die von [Decl.18] und [Decl.20].

\subsection{Hiat}

Außergewöhnlich niedrige Hiatraten, mit Werten bis zu 3\%, haben an normalen Wortfugen die folgenden Deklamationen: ${ }^{42}$ Decl.24 1.2\%, Decl.25 1.6\%, [Decl.49] 1.8\%, [Decl.51] 2.8\%, [Decl.40] 2.8\%, (Decl.6) 2.9\%, Decl.28 3.0\%. Hier konzentrieren sich also unechte und zweifelhafte Werke. Umgekehrt sind die mit den höchsten Hiatraten alle echt: Decl.27 10.1\%, Decl.13 8.3\%, Decl.32 8.0\%, Decl.8 7.6\%, Decl.7 7.5\%, Decl.31 7.4\%, Decl.42 7.4\%. ${ }^{43}$

40 Die ethologische Gruppe umfaßt Decl.26 bis [Decl.51], die mythologisch-historische Gruppe Decl.1 bis Decl.25. Die drei epideiktischen Deklamationen der mythologisch-historischen Gruppe (Decl.3, Decl.4 und Decl.5) fallen hier, anders als die epideiktischen Reden des Libanios, nicht weiter auf. Auch im Redenkorpus gehören die Monodien zu den Werken mit dem reichsten Vokabular, vgl. Sprachstatistische Untersuchungen 1, 133.

41 Tabulae 2.1, 370, unter ,Wl“" und ,z(Wl)“.

42 Tabulae 2.1, 379 unter ,\%H“.

43 Detaillierte Angaben zu Hiat, Elision und Krasis in Decl.3, Decl.4, Decl.5 und (Decl.6) - mit Listen der Einzelstellen - bei G. Pietsch, De Choricio Patrocli declamationis auctore (Breslauer Philologische Abhandlungen 42), Breslau 1910, 48-67. Dort 49: „Libanius, ut post longam vocalem hiatum summo cum studio evitat, ita brevium vocalium rationem omnino non habet ... Choricius autem ad tantum hiatus vitandi studium processit, ut non modo in longa, sed etiam in 
Vor diesem Hintergrund erhebt sich die Frage, ob es für die extrem niedrigen Hiatraten von Decl.24 und Decl.25 eine besondere Erklärung gibt. Es ist immerhin denkbar, daß Libanios die Strenge der beiden peloponnesischen Sprecher ${ }^{44}$ durch eine ebenso strenge Hiatvermeidung charakterisieren wollte, die sich ja, da Elision, Ny ephelkystikon und Krasis dafür nicht ausreichen, auch auf Wortwahl und Wortstellung auswirkt, ${ }^{45}$ und zwar derart, daß der Eindruck eines sehr bewußt formulierten, im günstigen Fall äußerst wohlgesetzten Ganzen entstehen kann. Andererseits wäre es möglich, die Echtheit von Decl.24 und Decl.25 in Frage zu stellen. Hermann v. Rohden ${ }^{46}$ und Paul Maas ${ }^{47}$ haben dies getan, letzterer auch aufgrund von Beobachtungen zur Klauselrhythmik. Foerster hat aber sicherlich recht mit der Bemerkung, daß ein solches Kriterium allein schwerlich ausreicht, ernste Zweifel an der Echtheit zu begründen. ${ }^{48}$ Eine Sonderstellung nimmt schließlich [Decl.49] ein, allein diese Deklamation zeigt eine penible, geradezu ängstliche Hiatvermeidung auch an Satzeinschnitten und Satzenden: ${ }^{49}$ Für Wortfugen mit Komma beträgt die Hiatrate nur $0.4 \%$, für solche an Satzenden nur 1.0\%. Damit wird sogar die Hiatrate von Decl.24 an einfachen Wortfugen unterboten. Im übrigen hat Decl.24 an Satzeinschnitten die zweitniedrigste Hiatrate, allerdings mit $4.8 \%$ schon einen nicht mehr ganz geringen Anteil.

brevi vocali maximam cautionem adhiberet. Hoc inde cognoscitur, quod verbis eligendis et collocandis efficere studet, ut etiam brevis vocalis cum altera concursus quam maxime evitetur, sed ita ut elisio vel crasis haud saepe adhibeatur."

44 Libanius VI, 436, Foerster zu Decl.24 „Archidamus accusatus quod legem quae triginta annis minorem contionari vetabat oratione de Messene retinenda habita laesisset se defendit“, und 463 zu Decl.25 ,unus e Corinthiis rogationi de Laide in urbem revocanda latae obloquitur“.

45 Einige Beobachtungen zu diesem Fragenkomplex bei D. Najock, Hiat und Satzklauseln in Plutarchs Vita des Tiberius Gracchus, in: Philologus 146 (2002) 87-110.

46 H. v. Rohden, De mundi miraculis quaestiones selectae, Diss. Bonn 1875, 34-41, konstatiert für Decl.24, Decl.25 und [Decl.49] eine strenge Hiatvermeidung selbst nach Artikel und $\kappa \alpha$,́, wie sie sonst erst in der Rhetorenschule von Gaza anzutreffen sei, gegen 500 n. Chr. (39f.). (Decl.6) zählt er zu den Werken, die fast ebenso geschrieben seien, ,quae eandem fere vitati hiatus rationem praestant", [Decl.34] und [Decl.45] sowie [Decl.40] und [Decl.43] zu den ähnlich, aber etwas freier geschriebenen (41 mit Anm. 16). Diese Einschätzungen finden ihre Bestätigung in der Hiatrate, Tabulae 2.1, 379 unter „\% $\% \mathrm{H}^{\prime}$.

47 P. Maas, Rezension zu Georgius Pietsch, De Choricio Patrocli declamationis auctore (Breslauer Philologische Abhandlungen 42), Breslau 1910, in: Wochenschrift für Klassische Philologie 28 (1911), Sp. 1253-1258, besonders Sp. 1255-1257. Maas gibt in seiner Rezension an, daß (Decl.6), Decl.24, Decl.25, Decl.27, Decl.32, Decl.37 und [Decl.49] das Meyersche Gesetz befolgen (zwischen den beiden letzten betonten Silben eines Satzes 2 oder 4 unbetonte). Außer Decl.27 hält er alle diese Werke für zweifelhaft und verweist dabei auch auf die strenge Hiatvermeidung in (Decl.6), Decl.24, Decl.25, Decl.37 und [Decl.49], die v. Rohden beobachtet hatte. Leider bleibt unklar, ob Maas die Klauseln aller Deklamationen geprüft hat. Anzumerken ist, daß Decl.37 mit einer Hiatrate von 3.4\% dem eingangs angeführten Extrembereich tatsächlich nicht allzu fern steht, während Decl.27 und Decl.32 mit 10.1\% und 8.0\% sehr hohe Hiatraten aufweisen.

48 Libanius VII, 641, Anm. 1.

49 Tabulae 2.1, 379, „\%H“ unter „Wortfugen mit Komma“ und „Wortfugen am Satzende“. 


\subsection{Mittlere Satzlänge}

Die mittere Satzlänge beträgt im Deklamationskorpus 16.6 Wörter. Die größten Abweichungen von diesem Wert, und zwar in beide Richtungen, liegen bei unechten Deklamationen. ${ }^{50}$ Im positiven Extrembereich sind es: [Decl.40] 26.2, [Decl.43] 24.5, Decl.37 24.3; im negativen: [Decl.34] 10.4, [Decl.20] 11.4, Decl.30 11.8. ${ }^{51}$ Werden Fragen und Aussagesätze gesondert betrachtet, so ändert sich nicht viel an diesem Bild. Im positiven Extrembereich ist allerdings bei Decl.37 ein stärkeres Ungleichgewicht zwischen der Länge der Fragen und der Aussagesätze festzustellen, und zwar zugunsten der letzteren (28.0 gegenüber 15.0). ${ }^{52}$ Im negativen Extrembereich bleiben [Decl.34] und [Decl.20] bei den Aussagesätzen weiterhin an der Spitze, doch schiebt sich Decl.33 vor Decl.30, bei den Fragesätzen aber ergibt sich, in der Reihenfolge zunehmender Länge (und abnehmender Signifikanz) folgende Gruppierung: [Decl.23] 7.1, Decl.26 7.5, Decl.12 7.6, [Decl.34] 7.6, Decl.30 8.6, Decl.46 8.7, [Decl.20] 9.2. Die zuvor angegebene Spitzengruppe [Decl.34], [Decl.20] und Decl.30 ist also insgesamt etwas in Richtung geringerer Signifikanz verschoben. Da die Fragen aber nur ein Viertel aller Sätze ausmachen, bleibt diese Verschiebung von untergeordneter Bedeutung. Im übrigen würde eine Sortierung nach Signifikanz [Decl. 34] an die zweite Stelle rücken, so daß wieder zwei unechte Deklamationen an der Spitze ständen. ${ }^{53}$ Die extremen Werte in der mittleren Satzlänge verstärken die Zweifel an der Echtheit von [Decl.40], [Decl.43], [Decl.34] und [Decl.20], und entsprechendes gilt für [Decl.23] speziell im Bereich der Fragesätze (bei einem Fragenanteil von $22 \%$ ).

\subsection{Mittlere Anzahl der Abschnitte pro Satz}

[Decl.34] und [Decl.20] haben nicht nur die kürzesten Sätze aller Deklamationen, sondern sie haben auch die geringste Anzahl von Abschnitten pro Satz. ${ }^{54}$ Daraus

50 Tabulae 2.1, 383 unter ,senl“.

51 Die zugehörigen z-Werte fallen, da Decl.37 und [Decl.20] ziemlich kurz sind, etwas anders aus: [Decl.40] z=10.98, [Decl.43] z=8.65, Decl.37 z=5.89; [Decl.34] z=-7.90, [Decl.20] z=-5.49, Decl.30 z=-6.94. Vgl. Tabulae 2.1, 383 unter „,z(senl)“. Decl.30 hebt sich durch den z-Wert von Decl.26 und Decl.46 ab, die in der mittleren Satzlänge selbst dicht auf Decl.30 folgen.

52 Decl.32 schließt sich in der Länge der Aussagesätze mit dem Wert 24.7 der Spitzengruppe an, bleibt aber in der Länge der Fragesätze mit 10.9 weit hinter dem Durchschnitt zurück.

53 Hier der negative Extrembereich für die Länge der Fragesätze mit Angabe der Signifikanz: [Decl.23] z=-5.10, Decl.26 z=-3.85, Decl.12 z=-3.27, [Decl.34] z=-3.94, Decl.30 z=-3.57, Decl.46 z=-2.78, [Decl.20] z=-1.62. Vgl. Tabulae 2.1, 383 unter ,z(quel)““.

54 Tabulae 2.1, 383, unter „,com/s“: [Decl.34] hat im Mittel 1.73, [Decl.20] im Mittel 1.85 Abschnitte pro Satz. 
ist nicht mehr zu folgern, als daß die Anzahl der Abschnitte in beiden Deklamationen der Satzlänge entspricht, daß also das Ausmaß der Untergliederung durch asyndetische Aufzählung, Antithese und Nebensatzbildung etwa auf dem Niveau des Durchschnitts liegt.

\subsection{Anteil der Fragen}

Im Deklamationskorpus sind ein Viertel aller Sätze Fragen. Sie sind in der Regel als rhetorische Fragen anzusehen, so daß der Fragenanteil bzw. seine Abweichung von dem genannten Durchschnitt (25\%) ein interessantes stilistisches Merkmal ist. Die Deklamationen mit einem hohen Fragenanteil von 30\% oder mehr zählen nun, wie die folgende Liste zeigt, fast alle zu den echten: ${ }^{55}$ Decl.41 39\%, Decl.44 37\%, Decl.27 35\%, Decl.14 33\%, Decl.22 32\%, Decl.38 32\%, Decl.39 31\%, Decl.1 31\%, [Decl.49] 31\%, Decl.50 30\%. Umgekehrt befinden sich unter denen mit besonders geringem Fragenanteil - bis zu 16\% - viele unechte: [Decl.29] 9\%, Decl.3 14\%, [Decl.18] 15\%, [Decl.20] 16\%, Decl.25 16\%. (Decl.15) und (Decl.16) liegen mit 17\% bzw. 18\% dicht an diesem Extrembereich, doch gibt es etliche echte Deklamationen mit solchen Werten. ${ }^{56} \mathrm{Zu}$ folgern ist, daß vor allem die Echtheit von [Decl.29] aufgrund des sehr geringen Anteils rhetorischer Fragen anzuzweifeln ist, daß aber auch die Außenseiterposition von [Decl.18] und [Decl. 20] bestätigt wird, dies freilich mit der Einschränkung, daß auch echte Deklamationen wie Decl.3 und Decl.25 solche Werte erreichen können.

\section{Verteilungsvergleiche}

\subsection{Funktionswörter}

Die auffälligsten Besonderheiten im Bereich der Funktionswörter seien hier zu Beginn in einer kleinen Liste zusammengestellt. Sie umfaßt diejenigen Lemmata, deren Residuen für bestimmte Deklamationen Werte von mindestens 7.0 oder höchstens -7.0 erreichen und damit extrem signifikante Abweichungen von der statistischen Erwartung anzeigen: Decl.1 $\dot{\varepsilon} \gamma \omega \dot{\mathrm{z}}=-14.1$, Decl.13 $\dot{\alpha} \lambda \lambda \dot{\eta} \lambda \omega \nu \mathrm{z}=13.9$,

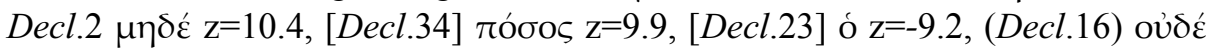

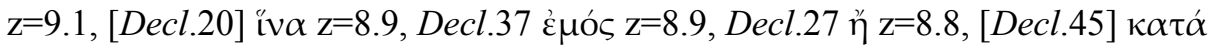

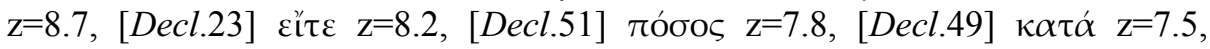

55 Tabulae 2.1, 383.

56 17\%: Decl.35 und Decl.48; 18\%: Decl.21, Decl.24 und Decl.33. 


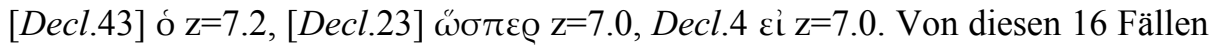
betreffen 10 die unechten oder angezweifelten Deklamationen, obwohl diese nur etwa ein Viertel des Deklamationskorpus ausmachen. ${ }^{57} \mathrm{Um}$ so bemerkenswerter ist es, daß die krassesten Fälle, $\dot{\varepsilon} \gamma \omega$ in Decl.1 und $\dot{\alpha} \lambda \lambda \eta \dot{\lambda} \lambda \omega v$ in Decl.13, zwei echte Deklamationen betreffen. ${ }^{58}$ Weiterhin fällt auf, daß 14 von 16 Residuen positiv sind, also besonders zahlreiche Vorkommen anzeigen, daß aber ausgerechnet der hervorstechendste Wert, -14.1 bei $\dot{\varepsilon} \gamma \omega$ in Decl.1, negativ ist und damit auf eine systematisch begründete Seltenheit des Personalpronomens der 1. Person deutet. Das ist für eine Apologie im allgemeinen nicht selbstverständlich, kann hier aber damit erklärt werden, daß Sokrates sich nicht selbst verteidigt, sondern ein Freund für ihn spricht.

Berücksichtigt man alle Residuen, die um wenigstens 4.5 von Null abweichen, so zeigt sich wiederum eine besondere Konzentration solcher Fälle in unechten und zweifelhaften Deklamationen. Es gibt 11 dieser immer noch hoch signifikanten Abweichungen in [Decl.49], 8 in [Decl.23], 7 in [Decl.43], 6 in [Decl.40], je 5 in [Decl.34], Decl.1 und Decl.27, sowie je 4 in [Decl.20], (Decl.16) und Decl.12. Dies sind alle Deklamationen mit vier oder mehr derartigen Abweichungen vom Durchschnitt. Die echten Werke nehmen hier noch geringeren Raum ein als in der ersten Liste, und die auffälligsten unter ihnen, Decl.1 und Decl.27, stehen auch weniger exponiert. Von Interesse sind besonders die

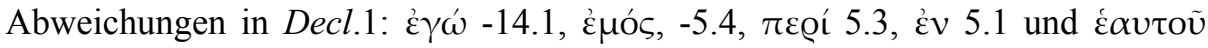
4.5; nimmt man noch $\dot{\varepsilon} \mu \alpha v \tau o \tilde{v}$ mit dem Residuum -3.9 hinzu, so ist vor allem ein dreifaches Unterschreiten der Erwartung bei den Pronomina der 1. Person zu konstatieren, daneben eine gewisse Vorliebe für präpositionale Ausdrücke mit $\dot{\varepsilon} v$ und $\pi \varepsilon$ Qí. $^{59}$

Im nächsten Schritt soll auch der Schwellenwert 4.5 fallengelassen und eine Größe betrachtet werden, die alle Einzelabweichungen zusammenfaßt, nämlich der aus einem Verteilungsvergleich, genauer aus einem Chi-Quadrat-Test, errechnete $\mathrm{z}$-Wert. ${ }^{60}$ Die Deklamationen mit der größten Gesamtabweichung sind die folgenden: ${ }^{61}$ [Decl.49] $\mathrm{z}=18.22$, [Decl.23] $\mathrm{z}=16.72$, Decl.1 $\mathrm{z}=16.11$, Decl.13 $\mathrm{z}=15.15$, [Decl.34] $\mathrm{z}=12.92,($ Decl.16) $\mathrm{z}=12.88$, [Decl.43] $\mathrm{z}=12.88$, [Decl.20] $\mathrm{z}=12.56$, Decl. $4 \mathrm{z}=12.48$, Decl.12 z=12.37. Darüber hinaus ist für echte Deklamationen $\mathrm{z}<12.00$. Daß Decl.1 und Decl.13 hier weit vorn unter den unechten Wer-

5713 der 51 Deklamationen gelten als unecht oder zweifelhaft, vgl. Abschnitt 1.1.

58 Decl.2, die an dritter Stelle steht, ist nicht frei von Zweifeln an der Authentizität.

59 Die Residuen von Decl.1 treten auch deshalb besonders stark hervor, weil Decl.1 mit 14367 Wörtern bei weitem die längste Deklamation ist, vor [Decl.23] mit 7760 Wörtern. Vgl. Tabulae $2.1,370$, unter , $\mathrm{Tl}$ “.

60 Die Umrechnung eines $\chi^{2}$-Wertes in einen $z$-Wert habe ich nach der Formel von Zevero/Zelen vorgenommen. $\mathrm{Zu}$ dieser und anderen Formeln vgl. Tabulae 2.1, XXI/XXII.

61 Tabulae 2.1, 370, unter, ,z(Fu)“. 
ken stehen, erklärt sich zu einem guten Teil aus den eingangs erwähnten extremen Abweichungen bei $\dot{\varepsilon} \gamma \omega \dot{\omega}$ und $\dot{\alpha} \lambda \lambda \eta \dot{\eta} \lambda \omega \nu$. Schneidet man die Liste bei $\mathrm{z}=12.50 \mathrm{ab}$, so bleiben Decl.1 und Decl.13 die einzigen echten Deklamationen der Spitzengruppe. Es soll aber angemerkt werden, daß Decl.4, wenn auch mit geringerer

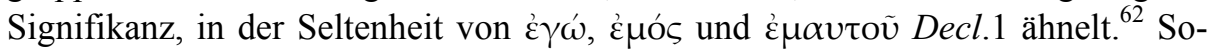
fern man Decl.1 und Decl.13 als erklärbare Ausnahmen betrachten kann, sprechen die Gesamtabweichungen gegen die Authentizität von [Decl.49], [Decl.23], [Decl.34], (Decl.16), [Decl.43] und [Decl.20], die relativ große Zahl hoch signifikanter Einzelabweichungen auch gegen die von [Decl.40].

In den Dendrogrammen, die den Prozeß der automatischen Klassifizierung widerspiegeln, ist die Position einer Deklamation außer durch ihre Abweichungen vom Durchschnitt auch durch die Ähnlichkeit zu anderen Deklamationen bestimmt. Ähneln sich zwei Deklamationen, so werden sie durch das Klassifikationsprogramm früh zu einer Kleingruppe zusammengefaßt, die dann später wiederum mit anderen, schon weniger ähnlichen Gruppen in größeren Familien vereinigt wird. Dabei gehen die Besonderheiten einer einzelnen Deklamation nach und nach im Gruppendurchschnitt unter. So kommt es, daß z.B. Decl.13, trotz $\mathrm{z}=15.15$, doch schließlich mit Decl. 2 verbunden wird und diese beiden dann, weil Decl.2 weniger abweicht, bald zum Gros des Deklamationskorpus stoßen, während Decl. 1 mit $\mathrm{z}=16.11$ bis zum Schluß des Fusionsprozesses isoliert bleibt. ${ }^{63}$ Sehr lange isoliert bleiben, wie an der Länge der Äste im Dendrogramm ablesbar ist, auch [Decl.49] und [Decl.23]. Außerdem stehen $\{[$ Decl.40],[Decl.43]\} und $\{($ Decl.15),(Decl.16)\} ziemlich isoliert, aber jeweils als Zweiergruppe. Schließlich bilden $\{[$ Decl.34],[Decl.45]\} und $\{[$ Decl.18],[Decl.20]\} eine Vierergruppe am Rande der sonst überwiegend echten Hauptfamilie. Man sieht also, daß die unechten und zweifelhaften Deklamationen dazu tendieren, im Dendrogramm entweder einzeln isoliert zu stehen oder mehr oder weniger isolierte Zweiergruppen zu bilden. Zwar gilt das auch für einige wenige echte, aber eben nur für wenige. Das Gros der echten Werke bildet in der automatischen Klassifikation eine große Familie von 32 Deklamationen, die [Decl.51] als einzige unechte und am Rande noch (Decl.6) einschließt. So gesehen bestärkt das Dendrogramm die Zweifel an der Authentizität vor allem von [Decl.49], [Decl.40], [Decl.43] und [Decl.23] sowie in etwas geringerem Grade auch von [Decl.34], [Decl.45], [Decl.18] und [Decl.20]. Da die vier letztgenannten Deklamationen aber weniger isoliert stehen als (Decl.15) und (Decl.16), sollte die Echtheit dieser beiden Werke ebenso in Frage gestellt werden.

Eine etwas abseits stehende Sondergruppe echter Deklamationen bilden Decl.3, Decl.4 und Decl.5. Diese Werke sind troischen Themen gewidmet, und

62 Ähnlich auch Decl.13, Decl.17 und [Decl.43].

63 Tabulae 2.1, 357. 
sie können, neben der ethologischen Monodie [Decl.51], als die einzigen epideiktischen Deklamationen gelten. ${ }^{64}$ Auch im Redenkorpus des Libanios sind die epideiktischen Reden in der Klassifikation nach Funktionswörtern mehr oder weniger deutlich abgesetzt, sie bilden dort aber keine geschlossene Gruppe. ${ }^{65}$ Die Deklamationen zeigen nun, daß der Einfluß der literarischen Gattung stärker sein kann als der der Autorschaft, denn die Gruppe $\{$ Decl.5, $\{$ Decl.3,Decl. 4$\}\}$ ist etwas weiter vom Gros der echten Deklamationen abgesetzt als $\{\{[$ Decl.34], $[$ Decl.45]\},\{[Decl.18],[Decl.20]\}\}.

\subsection{Allgemeinere Inhaltswörter}

Die größten Abweichungen vom Korpusdurchschnitt, gemessen in z-Werten, sind bei folgenden Deklamationen $\mathrm{zu}$ verzeichnen: ${ }^{66}$ [Decl.40] $\mathrm{z}=14.66$, Decl.12 $\mathrm{z}=14.22$, Decl.32 z=11.45, [Decl.49] z=11.32, [Decl.45] z=10.58, [Decl.23] $\mathrm{z}=10.32$, (Decl.15) z=10.02, Decl.13 z=10.02, [Decl.34] z=9.99, (Decl.16) $z=9.61$, (Decl.6) $z=9.49$. Wieder überwiegen also im Extrembereich die unechten und angezweifelten Werke, und wieder stehen bei diesen einzelne echte.

Die automatische Klassifikation bestätigt und ergänzt dieses Bild: ${ }^{67}$ Am weitesten abseits stehen Decl.12 und Decl.13, auch einander sehr unähnlich. Es folgt eine Reihe von ebenfalls sehr isoliert stehenden, meist unechten Einzeldeklamationen und Deklamationspaaren, nämlich [Decl.49], \{[Decl.40],[Decl.43]\}, (Decl.6), \{(Decl.15),(Decl.16)\}, \{[Decl.34],[Decl.45]\}, \{Decl.2,[Decl.23]\} und Decl.32. Hiervon abgesetzt erscheint, untereinander etwas enger verbunden, das Gros der echten Deklamationen, das, wenn auch nicht zentral, einzelne unechte einschließt, nämlich das Paar $\{[$ Decl.18],[Decl.20]\} sowie angelagert auch [Decl.29] und [Decl.51]. Obwohl keine scharfe Trennung der echten und unechten Deklamationen vorliegt, spricht doch das Dendrogramm für die vermutete Unechtheit von [Decl.49], [Decl.40], [Decl.43], (Decl.6), (Decl.15), (Decl.16), [Decl.34], [Decl.45] und wohl auch von [Decl.23]. [Decl.23] ist mit Decl.2 verbunden und wird deshalb, da Decl. 2 allein weniger vom Durchschnitt abweicht, ${ }^{68}$ dichter an das Gros der Deklamationen herangezogen. Zu erklären bleibt die exponierte Stellung von Decl.12, Decl.13 und Decl.32.

64 Schouler, Tradition (s. Anm. 5), I 28-34.

65 Sprachstatistische Untersuchungen 1, 155 und Tabulae 1, 609.

66 Tabulae $2.1,370$, unter, ,z(aI)“.

67 Tabulae 2.1, 358. Es sei angemerkt, daß die literarische Gattung hier nur noch eine untergeordnete Rolle spielt, denn unter den epideiktischen Deklamationen bilden nur Decl.3 und Decl.5 eine besondere Gruppe, während Decl.4 beim Gros der judizialen und deliberativen Deklamationen steht.

68 Decl.2 hat $\mathrm{z}=6.28,[$ Decl.23] aber $\mathrm{z}=10.32$. 
Erste Hinweise gibt schon eine Liste der höchsten Residuen. ${ }^{69}$ Mit Abstand

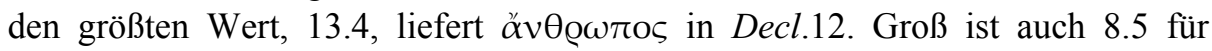

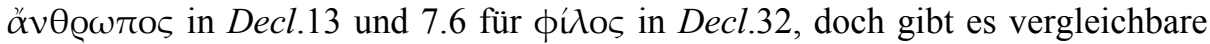
Fälle, die nicht immer zu einer exponierten Stellung der betreffenden Deklamationen geführt haben. ${ }^{70}$ Ein detaillierteres Bild ergibt sich, wenn alle Residuen ab 4.5 berücksichtigt werden. Diese immer noch hoch signifikanten Abweichungen vom Durchschnitt konzentrieren sich in vier Deklamationen: Je sechs liegen in Decl.32 und [Decl.40], je fünf in Decl.12 und [Decl.45]. Es sind also zwei echte und zwei unechte Deklamatonen, die sich nach diesem Kriterium besonders abheben, und dies um so mehr, als es keine Deklamationen mit vier solchen Abweichungen gibt; die Häufigkeit 3 ist dagegen öfter vertreten, fünfmal bei unechten und viermal bei echten. ${ }^{71}$ Im einzelnen sind für die vier auffälligen Deklamationen folgende Lemmata und Residuen zu nennen: Decl.32 („Avari scortum

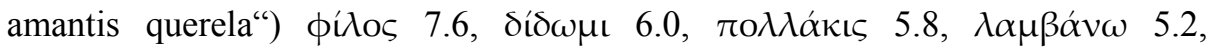

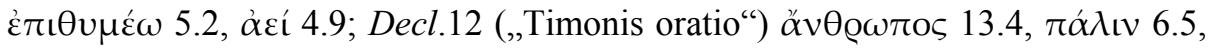

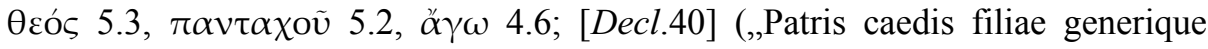

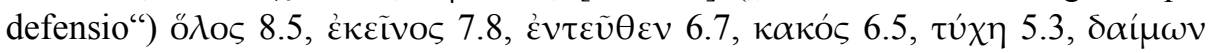

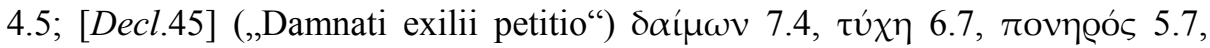

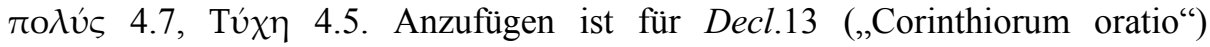

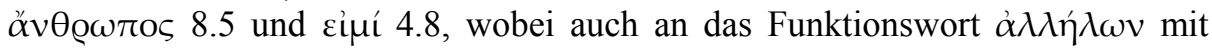
dem Residuum 13.9 zu erinnern ist.

Obwohl die allgemeineren Inhaltswörter möglichst nicht an bestimmte Themen gebunden sein sollten, zeigen diese Listen doch einen Einfluß des Deklamationsthemas und der argumentativen Topoi. In [Decl.40] und [Decl.45] äußert sich dies in einem verstärkten, gegenüber den echten Deklamationen überzogenen

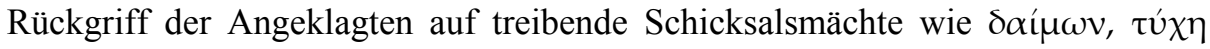

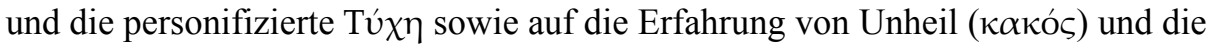

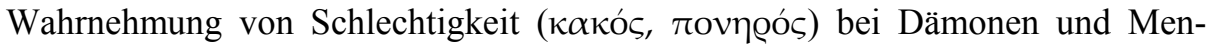
schen. ${ }^{72}$ In Decl.12 bittet der Misanthrop Timon die Athener Geschworenen um ein Todesurteil, weil er es nicht ertragen kann, in Liebe zu Alkibiades verfallen zu sein. Seine Abscheu gegenüber den Menschen malt er breit aus, sogar die Götter-

69 Tabulae 2.1, 323-328, „Chi-Quadrat-Test der häufigen allgemeineren Inhaltswörter““.

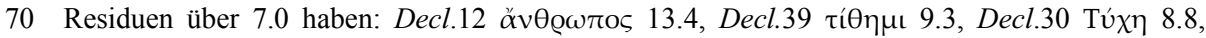

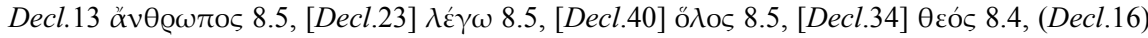

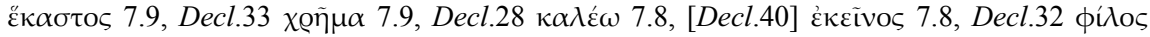

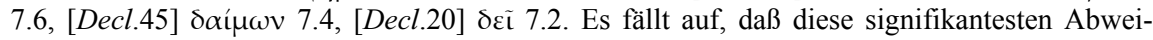
chungen alle positiv sind, also auffällige Häufungen anzeigen. Negative Abweichungen hoher Signifikanz sind auch bei den Funktionswörtern selten.

71 Drei hoch signifikante Einzelabweichungen haben Decl.2, (Decl.6), Decl.8, Decl.24, Decl.28, [Decl.34], [Decl.43], [Decl.49] und [Decl.51].

72 Letzteres zu einem kleinen Teil auch hypothetisch. 
bilder haßt er wegen ihrer menschlichen Gestalt, Alkibiades aber vergöttlicht er. So erklärt sich die auffällige Häufigkeit von $\theta \varepsilon$ ćs und ganz besonders die von ăv$\theta 0 \omega \pi \circ \varsigma$ hier doch aus dem speziellen Inhalt und aus dem Charakter des Sprechers, und ähnlich die von $\pi \alpha v \tau \alpha \chi \chi \tilde{v}$ aus seiner zu rhetorischer Häufung und zur Hyperbel neigenden exaltierten Sprechweise. In Decl.32 bittet - ebenfalls in eigener Sache - ein Geizhals, der einer Hetäre verfallen ist, den Stadtrat um den Schierlingsbecher, als diese Geld von ihm fordert. Es ist leicht zu verstehen, daß

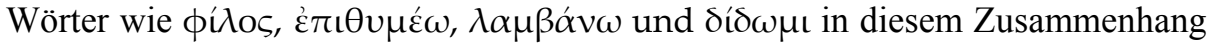

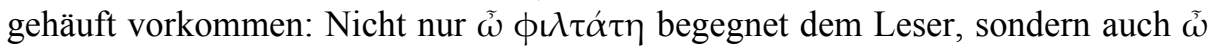

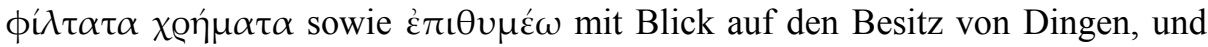
ebenso dienen $\lambda \alpha \mu \beta \alpha ́ v \omega$ und $\delta i \delta \omega \mu$ vielfach zur Charakterisierung des Spre-

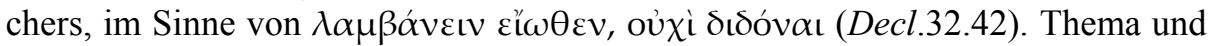
Charakterisierung des Sprechers tragen also auch hier zu den hoch signifikanten Residuen bei. In Decl.13 werden die Athener wegen Asebie verklagt, weil sie bei der Belagerung von Potidaia (430 v. Chr.) die Bewohner der Stadt zum Kannibalismus getrieben hätten. ${ }^{73}$ Es ist fast unvermeidlich, daß őv $\theta \varrho \omega \pi o \varsigma$ in diesem Zusammenhang gehäuft auftritt, ebenso wie das Pronomen $\alpha \lambda \lambda \eta \dot{\eta} \lambda \omega v$, das schon

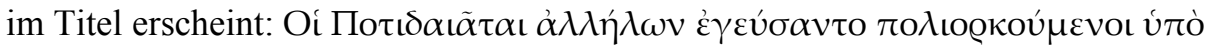

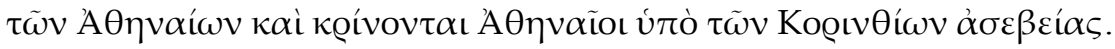

Trotz des inhaltlichen Einflusses ist offenbar auch die Autorschaft ein sehr wichtiger Faktor, denn die Deklamationen mit großer Gesamtabweichung vom Korpusdurchschnitt sind, wie zu Beginn dieses Abschnitts dargelegt, ganz überwiegend unechte und angezweifelte Werke. Die beiden wichtigsten Ausnahmen, Decl.12 und Decl.32, sind, wie die Untersuchung der Residuen gezeigt hat, aufgrund des Themas und einer besonderen Darstellungsabsicht in eine ebenso exponierte Position geraten, und ähnliches gilt - in schwächerem Grade - für Decl.13. Beide Faktoren vermischen sich im Ergebnis und sind dann unter Umständen schwer voneinander zu trennen. Eine Sonderstellung hinsichtlich der allgemeineren Inhaltswörter ist also nur mit gewissem Vorbehalt als Hinweis auf die Unechtheit anzusehen, mit dem Vorbehalt nämlich, daß eine besondere Abweichung vom Durchschnitt manchmal auch mit der Thematik und einer besonderen Absicht des Libanios erklärt werden kann. Ist eine solche Begründung nicht zu finden, wird man Zweifel an der Authentizität hegen dürfen, insbesondere dann, wenn auch entsprechende Indizien anderer Art vorliegen.

73 Inhaltlich ist die Deklamation an Thukydides 2.70 angelehnt. 


\subsection{Wortarten}

Die automatische Klassifikation nach Wortartenverteilungen führt zu zwei sehr deutlich voneinander getrennten und in sich jeweils ziemlich eng geschlossenen Gruppen, deren erste nur mythologisch-historische Deklamationen und deren zweite fast ausschließlich ethologische Deklamationen umfaßt. ${ }^{74}$ Einzige Ausnahme in der zweiten Gruppe ist das Paar $\{($ Decl.15),(Decl.16) $\}$, das sehr isoliert steht, dabei aber doch etwas enger mit den ethologischen Deklamationen verbunden ist. Innerhalb der ersten Gruppe stehen etwas abseits zwei Untergruppen, die jeweils zur Hälfte aus unechten Deklamationen bestehen, nämlich $\{$ Decl.12, $\{$ Decl.19, $\{[$ Decl.18],[Decl.20]\}\}\} und $\{$ Decl.2,[Decl.23]\}, innerhalb der zweiten Familie, den ethologischen Deklamationen, steht ähnlich abseits die Untergruppe $\{\{[$ Decl.40],[Decl.43]\},\{Decl.37,\{[Decl.29], [Decl.49]\}\}\}, die sogar $\mathrm{zu}$ vier Fünfteln aus unechten besteht. So wird hier offenbar doch ein Einfluß der Autorschaft sichtbar, wenn er auch bei weitem nicht an den des thematischen Gegensatzes heranreicht.

Die Ursache für die klare Abgrenzung der ethologischen Deklamationen von den mythologisch-historischen ist, wie die Residuen des Chi-Quadrat-Tests zeigen ${ }^{75}$ die große Häufigkeit der Eigennamen in den meisten der letzteren, die automatisch dazu führt, daß eben Eigennamen in allen ethologischen Deklamationen stark unterrepräsentiert sind, zumeist sogar mit sehr hoher Signifikanz: 19 der 26 Residuen liegen zwischen -7.0 und -11.0 , vier weitere noch zwischen -6.2 und $-6.7 .^{76}$ Dem stehen auf seiten der mythologisch-historischen Deklamationen, wenn auch nicht so durchgängig, positive Residuen oft noch höherer Signifikanz gegenüber: 10 der 25 Werte liegen zwischen 9.5 und 21.8, vier weitere zwischen 6.1 und 6.9. Einige judiziale Deklamationen dieser Gruppe bleiben aber in der Nähe oder sogar unterhalb des Durchschnitts: Decl.7, Decl.8, Decl.9 und Decl.10. Unter den deliberativen Deklamationen der mythologisch-historischen Gruppe gibt es nur zwei Ausnahmen, (Decl.16) mit durchschnittlichem und (Decl.15) mit unterdurchschnittlichem Eigennamenanteil. Hinzu kommt, daß unter den mythologisch-historischen Deklamationen eben (Decl.15) und (Decl.16) den durchschnittlichen Adjektivanteil mit hoch signifikanten Residuen (7.3 und 6.2) überschreiten und daß sie in diesem Punkt mehr den ethologischen Deklamationen

74 Tabulae 2.1, 359.

75 Tabulae 2.1, 346f.

76 Anzumerken ist ferner, daß dort, wo die Eigennamen besonders häufig sind, also in den mythologisch-historischen Deklamationen, die Substantive meist selten sind. Umgekehrt sind - und das muß dann so sein - die Substantive in den ethologischen Deklamationen meist vergleichsweise häufig. Die Ursache dieses Phänomens liegt darin, daß Satzpositionen, die in der ersten Gruppe mit Eigennamen besetzt sind, in der zweiten öfter von Substantiven eingenommen werden. 
ähneln. Die Verwandtschaft von (Decl.15) und (Decl.16) zeigt sich ferner darin, daß unterordnende Konjunktionen in beiden überrepräsentiert sind, Interjektionen und Verben aber unterrepräsentiert, letzteres mit hoch signifikanten Residuen (4.7 und -6.3). In diesen drei Punkten ähneln sie eher der Mehrheit der mythologisch-historischen Deklamationen. Damit ist die Sonderstellung, die das Paar $\{($ Decl.15), (Decl.16) $\}$ in der automatischen Klassifikation erhält, hinreichend erklärt. Wollte man die Wortartenverteilung als Hauptkriterium zur Beurteilung der Echtheitsfrage heranziehen, so müßten es vor allem diese beiden Deklamationen sein, die, eben weil sie in der Summe ihrer Eigentümlichkeiten in der Wortartenverteilung völlig isoliert stehen, den stärksten Zweifeln an der Authentizität unterliegen sollten.

In den individuellen Abweichungen vom Korpusdurchschnitt, gemessen in zWerten, liegen drei andere Deklamationen an der Spitze: ${ }^{77}[$ Decl.23] $\mathrm{z}=18.73$, Decl.2 z=16.46, [Decl.20] z=15.57. Diese Werte sind in hohem Maße durch den Eigennamenanteil mitbestimmt, tatsächlich weisen eben diese drei Deklamationen die höchsten Residuen bei den Eigennamen auf: ${ }^{78}$ [Decl.23] 21.8, Decl.2 18.5, [Decl.20] 17.4. Obwohl sich hier die thematische Zweiteilung niederschlägt, werden doch durch die extreme Positionierung die Zweifel an der Authentizität von [Decl.23], Decl.2 und [Decl.20] gestärkt.

\subsection{Buchstaben}

Wie in der Einleitung erwähnt, sollten die Buchstabenverteilungen einige Hinweise in der Echtheitsfrage geben. Tatsächlich sind die Deklamationen mit der größten Gesamtabweichung vom durchschnittlichen Buchstabenbestand alle unecht bzw. zweifelhaft: ${ }^{79}$ [Decl.23] z=13.36, [Decl.49] z=12.66, (Decl.16) z=12.57, [Decl.43] z=12.10, [Decl.40] z=11.34, (Decl.15) $\mathrm{z}=11.15$, Decl. $12 \mathrm{z}=11.14{ }^{80}$ Es folgen dann in einem gewissen Abstand Decl.13 mit z=9.90 und Decl.2 mit $\mathrm{z}=9.78$.

Die automatische Klassifikation bestätigt dieses Bild: ${ }^{81}$ Abseits vom Gros des Korpus stehen [Decl.49], [Decl.43], [Decl.40], \{(Decl.15),(Decl.16)\} und [Decl.23], relativ isoliert am Rande dieses Gros außerdem [Decl. 34]. Ziemlich abseits steht auch die Kleingruppe $\{$ Decl.13,[Decl.20]\}, wobei hier Decl.13 durch

77 Tabulae 2.1, 370, unter, ,z(Wa)“.

78 Tabulae 2.1, 346f.

79 Tabulae 2.1, 370, unter, ,z(Bu)“ und , $\chi^{2}(\mathrm{Bu})^{“}$.

80 Diese $z$-Werte sind nach der Formel von Zevero/Zelen aus den $\chi^{2}$-Werten 281.2, 256.8, 253.7, 238.2, 214.6, 208.8 und 208.7 abgeleitet. Dies sind alle Abweichungen mit $\chi^{2}$-Werten über 200.0. Vgl. Tabulae 2.1, XXI/XXII.

81 Tabulae 2.1, 360. 
[Decl.20] dichter an das Gros herangezogen wird, denn [Decl.20] hat nur $\mathrm{z}=8.21$ (gegenüber $\mathrm{z}=9.90$ bei Decl.13). Daher erscheint denn auch Decl.2 im Dendrogramm stärker isoliert als Decl.13, obwohl Decl.13 den höheren z-Wert hat.

So sprechen die Buchstabenverteilungen ziemlich deutlich gegen die Authentizität von [Decl.23], [Decl.49], (Decl.16), [Decl.43], [Decl.40] und (Decl.15), in geringerem Maße auch gegen die von [Decl.34] und vielleicht auch ein wenig gegen die von (Decl.6). Den Ursachen bei den einzelnen Buchstaben nachzugehen ist sinnlos, da die auffallende Häufigkeit oder Seltenheit eines Buchstabens kaum interpretierbar ist. Immerhin zeigt sich aber in der Residuentabelle eine weitgehende Parallelität der Buchstabenverteilungen bei (Decl.15) und (Decl.16): $:^{82} \mathrm{E}$ ist selten, I und $\mathrm{K}$ sind häufig, $\Lambda, \mathrm{N}$ und $\Pi$ selten, $\Sigma, \Upsilon$ und $\Phi$ häufig, $\Omega$ wieder selten, dies alles mit signifikanten Abweichungen vom Durchschnitt. (Decl.15) und (Decl.16) sind einander so ähnlich wie ein durchschnittliches Paar aus dem Gros der echten Deklamationen. Das bestärkt die Ansicht, daß beide ein und demselben Autor zuzuschreiben sind.

Bemerkenswert ist schließlich, daß auch Decl.12, Decl.13 und Decl.2 dem Durchschnitt ziemlich unähnlich sind, doch ist Decl.12 in eine Nebengruppe eingebunden und erscheint daher weniger isoliert. 


\section{Deklamationspaare}

\subsection{Gruppenbildung}

Es fällt auf, daß die automatische Klassifikation bestimmte Deklamationspaare mehrfach, d.h. nach mehr als nur einem Kriterium zusammenführt. Eine Übersicht gibt die folgende Tabelle, in welcher das Auftreten als Paar durch ein X gekennzeichnet ist. ${ }^{83}$

\begin{tabular}{|c|c|c|c|c|}
\hline $\begin{array}{c}\text { Klassifikations- } \\
\text { kriterium: }\end{array}$ & $\begin{array}{c}\text { Funktions- } \\
\text { wörter }\end{array}$ & $\begin{array}{c}\text { allgemeinere } \\
\text { Inhaltswörter }\end{array}$ & Wortarten & $\begin{array}{c}\text { Buchstaben- } \\
\text { verteilung }\end{array}$ \\
\hline$\{($ Decl.15),(Decl.16) $\}$ & $\mathrm{X}$ & $\mathrm{X}$ & $\mathrm{X}$ & $\mathrm{X}$ \\
\hline$\{[$ Decl. 40$],[$ Decl. 43$]\}$ & $\mathrm{X}$ & $\mathrm{X}$ & $\mathrm{X}$ & - \\
\hline$\{[$ Decl. 18$],[$ Decl. 20$]\}$ & $\mathrm{X}$ & $\mathrm{X}$ & $\mathrm{X}$ & - \\
\hline$\{[$ Decl.51],Decl. 28$\}$ & $\mathrm{X}$ & $\mathrm{X}$ & - & $\mathrm{X}$ \\
\hline$\{$ Decl.24,Decl. 25$\}$ & $\mathrm{X}$ & $\mathrm{X}$ & $\mathrm{X}$ & - \\
\hline$\{[$ Decl.23],Decl. 2$\}$ & - & $\mathrm{X}$ & $\mathrm{X}$ & - \\
\hline$\{[$ Decl.34],[Decl.45] $\}$ & $\mathrm{X}$ & $\mathrm{X}$ & - & - \\
\hline
\end{tabular}

Tabelle 1: Paarbildung in den automatischen Klassifikationen.

Größere Gruppen unechter oder zweifelhafter Deklamationen wiederholen sich nicht. Überraschenderweise stehen sich die meisten der so zusammengeführten Paare auch in den eindimensionalen Skalierungen sehr nahe. Das zeigt die folgende Tabelle, in der jeweils die Anzahl anderer Deklamationen angegeben ist, die ein Paar in einer bestimmten Skalierung trennen. ${ }^{84}$

83 Tabulae 2.1,357-360.

84 Als trennend sind diejenigen Deklamationen gezählt worden, deren Wert echt innerhalb des zu einem Paar gehörigen Intervalls liegt. Liegt ein Wert auf einer Intervallgrenze selbst, was ab und zu vorkommt, so ist die betreffende Deklamation nicht als trennend behandelt worden. Der

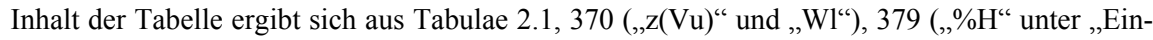
fache Wortfugen“) und 383 (,senl“ und „que/s“). Die mittlere Anzahl der Abschnitte pro Satz ist in der Tabelle nicht berücksichtigt, da sie gegenüber der mittleren Satzlänge nicht viel Neues bietet, die Dichte der Erstbelege nicht, weil die meisten Deklamationen keine oder nur sehr wenige Erstbelege enthalten, so daß das Korpus nur sehr grob aufgefächert wird, zu grob, um in der Anzahl trennender Deklamationen ein sinnvolles Kriterium für die Ähnlichkeit zu liefern. 


\begin{tabular}{|c|c|c|c|c|c|}
\hline Skalierung nach: & $\begin{array}{c}\text { Vokabular- } \\
\text { umfang }\end{array}$ & $\begin{array}{c}\text { mittlere } \\
\text { Wortlänge }\end{array}$ & Hiatrate & $\begin{array}{c}\text { mittlere } \\
\text { Satzlänge }\end{array}$ & $\begin{array}{c}\text { Fragen- } \\
\text { anteil }\end{array}$ \\
\hline$\{($ Decl.15),(Decl.16)\} & $\begin{array}{c}\text { einige } \\
(7)\end{array}$ & 0 & 1 & $\begin{array}{c}\text { viele } \\
(12)\end{array}$ & 0 \\
\hline$\{[$ Decl.40],[Decl.43]\} & 2 & $\begin{array}{c}\text { viele } \\
(11)\end{array}$ & 2 & 0 & 1 \\
\hline$\{[$ Decl.18],[Decl.20]\} & $\begin{array}{c}\text { viele } \\
(25)\end{array}$ & 1 & 4 & 4 & 0 \\
\hline$\{[$ Decl.51],Decl.28\} & 1 & 1 & 1 & $\begin{array}{c}\text { viele } \\
(22)\end{array}$ & $\begin{array}{c}\text { viele } \\
(15)\end{array}$ \\
\hline$\{$ Decl.24,Decl.25\} & 0 & 0 & 0 & $\begin{array}{c}\text { viele } \\
(12)\end{array}$ & 3 \\
\hline$\{[$ Decl.23],Decl.2\} & 1 & 0 & $\begin{array}{c}\text { viele } \\
(12)\end{array}$ & $\begin{array}{c}\text { viele } \\
(30)\end{array}$ & 3 \\
\hline$\{[$ Decl.34],[Decl.45]\} & $\begin{array}{c}\text { viele } \\
(12)\end{array}$ & $\begin{array}{c}\text { viele } \\
(25)\end{array}$ & 0 & $\begin{array}{c}\text { viele } \\
(18)\end{array}$ & $\begin{array}{c}\text { viele } \\
(16)\end{array}$ \\
\hline
\end{tabular}

Tabelle 2: Trennende Deklamationen in den eindimensionalen Skalierungen.

Außer [Decl.34] und [Decl.45] stehen also die in der automatischen Klassifikation mehrfach zusammengeführten Paare in den linearen Skalierungen jeweils mindestens dreimal in enger oder unmittelbarer Nachbarschaft. Die weitgehende Ähnlichkeit von Decl.24 und Decl.25 kann vielleicht zu einem Teil auf besondere Darstellungsabsichten des Libanios zurückgeführt werden. ${ }^{85}$ Darüber hinaus aber könnte die Nähe in so vielen Merkmalen dafür sprechen, daß die Paare $\{($ Decl.15),(Decl.16) $\},\{[$ Decl.40],[Decl.43]\}, \{[Decl.18],[Decl.20]\}, \{[Decl.51], Decl.28\} und $\{[$ Decl.23], Decl.2\} jeweils ein und demselben Autor zuzuweisen sind. Für $\{($ Decl.15),(Decl.16) $\}$ und $\{[$ Decl.40],[Decl.43]\} hat Foerster das ohnehin angenommen. ${ }^{86}$ Von besonderem Interesse sind die beiden letzten Paare, in denen jeweils eine echte Deklamation mit einer unechten verbunden ist. Man wird sich also ernsthaft fragen müssen, ob z.B. Decl.28 auch als unecht oder [Decl.51] doch als echt anzusehen ist, und das gilt ebenso für Decl.2 und [Decl.23]. Im folgenden werden die Deklamationspaare einzeln besprochen.

85 Vgl. Abschnitt 2.3.

86 Schon H. v. Rohden (s. Anm. 46), 41, Anm. 16, erwägt eine engere Zusammengehörigkeit von [Decl.40] und [Decl.43]. Nachdem er nämlich die Vermutung ausgesprochen hat, daß [Decl.34] und [Decl.45] einem und demselben Autor zuzuweisen seien, fährt er so fort: „his nescio num

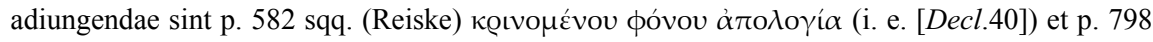

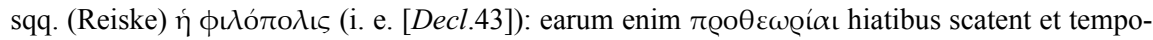
re multo recentiore scriptae videntur, ipsae autem declamationes paullulum a scribendi quae in ceteris conspicitur ratione abhorrent." 


\section{2 (Decl.15) und (Decl.16)}

(Decl.15) und (Decl.16) sind von vornherein als Paar zusammengehöriger Deklamationen überliefert und als solches schon in der Spätantike bekannt, wobei die ältesten Zeugen - Syrianos (1. Hälfte 5. Jh. n. Chr.), Sopatros (4. oder 5. Jh. n. Chr.) und andere ${ }^{87}$ - keinen Autor kennen und erst Johannes Doxapatres (1. Hälfte 11. Jh.) Libanios angibt. Die beiden Deklamationen sind miteinander konkurrierende Bewerbungen um eine öffentliche Belohnung für eine gute Lebensführung. Aristophon, in (Decl.16), begründet seinen Anspruch damit, daß er $75 \mathrm{mal}$ wegen Gesetzwidrigkeit $(\pi \alpha \varrho \alpha \nu o ́ \mu \omega \nu)$ angeklagt, aber niemals einer Schuld überführt worden sei. Kephalos, in (Decl.15), führt dagegen an, daß er, obwohl er zahllose Beschlußvorlagen verfaßt habe, niemals auch nur der Gesetzwidrigkeit angeklagt gewesen sei.

Foerster äußert einige Zweifel an der Echtheit des Paares, neben einem inhaltlichen Fehler Besonderheiten der Diktion, „elocutionis quaedam proprietates“, und vor allem der Wortwahl, „imprimisque delectus verborum“, er gibt aber, da die Angelegenheit den Rahmen der Praefatio sprengen würde, „cum fines huic praefationi impositos excedat", keine Beispiele, sondern vertröstet den Leser auf eine spätere Gelegenheit, ,alia occasione utar“. ${ }^{88}$ Verglichen mit den umfangreichen Listen in den Praefationes zu [Decl.40] und [Decl.43] dürfte man hier also noch umfangreicheres Material erwarten. Jedenfalls hat dieses Material wohl Zweifel an der Echtheit von (Decl.15) und (Decl.16) genährt, nicht aber an der Zusammengehörigkeit der beiden Deklamationen. Man kann vermuten, daß Libanios den unterschiedlichen Charakter der beiden Politiker Aristophon und Kephalos in ihrer Sprechweise hätte zum Ausdruck bringen wollen und daß dann eine weniger enge Übereinstimmung in den hier untersuchten statistischen Merkmalen hätte zutage treten sollen. Das spräche dann eher gegen seine Autorschaft.

In den eindimensionalen Merkmalen bleiben (Decl.15) und (Decl.16) unauffällig. ${ }^{89}$ Die vier Verteilungsvergleiche aber zeigen, daß (Decl.15) und (Decl.16) in den Gesamtabweichungen vom Korpusdurchschnitt öfter zur Spitzengruppe überwiegend unechter Deklamationen gehören, (Decl.16) bei den Funktionswörtern, (Decl.15) bei den allgemeineren Inhaltswörtern und beide bei den Buchstabenverteilungen. Dabei sind sie einander so verwandt, daß sie in allen vier Klassifikationen ein eng zusammengehöriges Paar bilden und zusammen ziemlich isoliert stehen, in der Klassifikation nach Wortartenverteilungen sogar außerhalb der Gruppe mythologisch-historischer Deklamationen und als Paar weitaus iso-

87 Libanius VI, 111.

88 Libanius VI, 110f., Anm. 3.

89 (Decl.15) und (Decl.16) haben einen ziemlich geringen Fragenanteil, doch stehen sie damit in der Nachbarschaft einiger echter Deklamationen. 
lierter als alle anderen Deklamationen oder Deklamationsgruppen. So zeigt sich insgesamt eine Sonderrolle von (Decl.15) und (Decl.16), die gegen ihre Authentizität spricht. $^{90}$

\section{$4.3[$ Decl.40] und [Decl.43]}

In den Praefationes zu [Decl.40] und [Decl.43] führt Foerster eine ganze Reihe von Gemeinsamkeiten dieser beiden Deklamationen an, teils in allgemeinerer Form, teils im Detail belegt. ${ }^{91}$ Zur ersten Gruppe gehören: (a) Mangel an Grazie und Schlichtheit, „gratia atque simplicitas ... desiderantur“, (b) Unebenheit und Weitschweifigkeit, „regnant asperitas atque verbositas“, (c) ausufernder Satzbau, „longae enuntiatorum ambages“, mit einzelnen Beispielen, (d) eine Vorliebe für

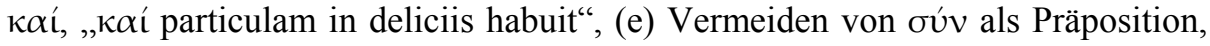
„praepositionem oúv vitavit“, sowie Vermischung von $\xi v v-$ und $\sigma v v-$ als Präfix, (f) besondere Nachlässigkeit dem Hiat gegenüber, ,concinunt ... singulari in hiatu vitando socordia“". Im Detail belegt sind: (g) Verwendung poetischen Vokabulars, „intermixta sunt vocabula poetica“, (h) zahlreiche Komposita mit zwei oder mehr Präfixen, (i) Relativsätze nach Artikel, (j) Indikativ Futur statt Konjunktiv Aorist, (k) Infinitiv Futur statt Infinitiv Präsens oder Aorist, (l) kăv mit Indikativ Aorist

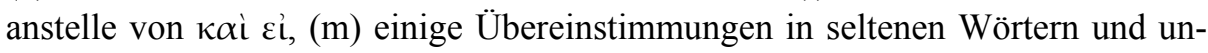

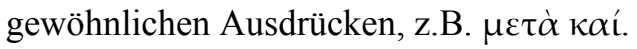

Unter diesen Besonderheiten dienen einige vor allem dem Nachweis der Unechtheit, so (a), (b), (c), (d), (e), (g) und (h), die übrigen aber, nämlich (f) und (i), (j), (k), (1), (m), sollen zeigen, daß [Decl.40] und [Decl.43] ein und demselben Autor zuzuschreiben sind. Dem ist im großen und ganzen zuzustimmen, ein Punkt aber, nämlich (f), ist zu streichen: Die Hiatrate ist nach Ausweis unserer Statistik in beiden Deklamationen gering. ${ }^{92}$ Auch ist Punkt (e) in seinem ersten Teil nicht aussagekräftig: Zwar ist oúv als Präposition in beiden Deklamationen sehr selten, ${ }^{93}$ doch gilt das hier allgemein, denn in 33 der 51 Deklamationen kommt oúv gar nicht vor. ${ }^{94}$

Bestätigt werden durch die statistischen Tabellen die Punkte (d) und (c), und

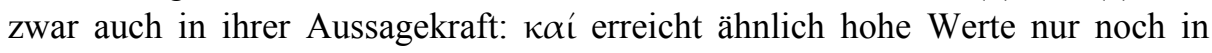

90 Könnte man (Decl.15) und (Decl.16) eine Mittelstellung zwischen ethologischen und mythologisch-historischen Deklamationen zuweisen, so wäre damit die merkwürdige Position in der Klassifikation nach Wortartenverteilungen teilweise erklärt, nicht aber die Außenseiterpositionen in den drei anderen Klassifikationen.

91 Libanius VII, 317-321 und 431-433.

92 Tabulae 2.1, 379.

$93 \Sigma$ ¿úv fehlt in [Decl.40] und tritt in [Decl.43] nur einmal auf.

94 Tabulae 2.1, 88 und 185. 
Decl.2, Decl.12 und [Decl.29], ${ }^{95}$ und in der mittleren Satzlänge, auch bei den Fragen, liegen [Decl.40] und [Decl.43] an der Spitze aller Deklamationen. ${ }^{96}$ Darüber hinaus gibt es keine Überschneidungen der von Foerster vorgebrachten Punkte mit den statistischen Ergebnissen. Auch nach Streichung von (f) und teilweise (e) bleibt Foersters Material überzeugend. Seine Schlußfolgerungen werden durch die weiter oben angeführten statistischen Ergebnisse bestätigt: Nicht nur $\kappa \alpha$ í, sondern die häufigen Funktionswörter insgesamt wie auch die allgemeineren Inhaltswörter und die Wortartenverteilungen belegen die enge Zusammengehörigkeit von [Decl.40] und [Decl.43] sowie ihre Verschiedenheit vom restlichen Korpus; auch in der Armut des Vokabulars und im Anteil der rhetorischen Fragen liegen sie sehr dicht beieinander, ebenso in der, wie schon erwähnt, ziemlich niedrigen (!) Hiatrate. Die auffallendsten Übereinstimmungen bei den Funktions-

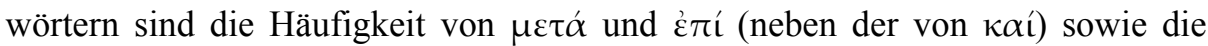
Seltenheit von $\dot{\varepsilon} v$, $\gamma \alpha \dot{Q} \varrho$ und $\eta_{\eta}{ }^{97}$ Bei den allgemeineren Inhaltswörtern ist es die

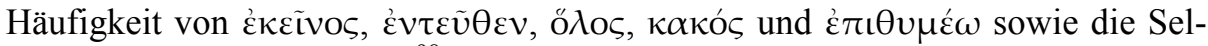

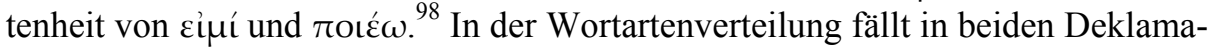
tionen die Häufigkeit der Pronomina und besonders die Seltenheit der Verben auf. $^{99}$ In diesem letzten Punkt unterscheiden sich [Decl.40] und [Decl.43] von allen anderen ethologischen Deklamationen.

Gerade in den Praefationes zu [Decl.40] und [Decl.43] sind zahlreiche sonst nicht bei Libanios belegte Wörter angeführt, ,magna copia vocabulorum ab usu Libanii alienorum". Man muß dies vor dem Hintergrund sehen, daß genau einmal belegte Wörter überhaupt sehr zahlreich sind: Es sind 2528 der insgesamt 7027 Lemmata in den Deklamationen, also über ein Drittel des Wortschatzes. ${ }^{100} \mathrm{Im}$ merhin gibt die Länge von Foersters Listen zu denken. Wichtiger ist die Frage, ob sich hier für Libanios akzeptable Belegautoren finden lassen, und besonderes Augenmerk verdienen diejenigen Wörter, die bis hin zu Libanios nicht belegt sind. Foerster führt für [Decl.40] 30 Wörter an, die er dem Libanios absprechen möchte, ${ }^{101}$ aber nur sechs davon sind solche, für die es keine Belegautoren vor

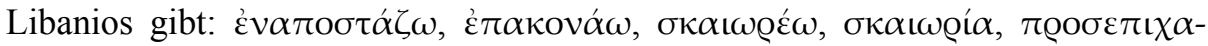

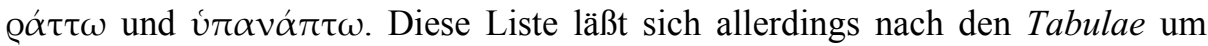

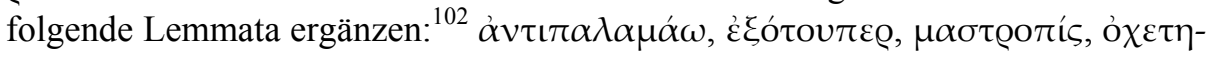

95 Tabulae 2.1, 297-299.

96 Tabulae 2.1, 383.

97 Tabulae 2.1, 299 und 303.

98 Tabulae 2.1, 326 und 332.

99 Tabulae 2.1, 347.

100 Tabulae 2.1, 367f. Die Gesamtzahl 7027 ist die Summe der dort unter „v(i)“ aufgeführten Zahlen.

101 Libanius VII, 318.

102 Tabulae 2.2, 605f., und Tabulae 2.1, 3-198, „Häufigkeitstabelle zum Vokabular der Deklamationen“. 


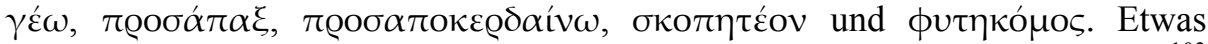
besser steht es um [Decl.43]. Unter den 27 von Foerster angegebenen Wörtern ${ }^{103}$

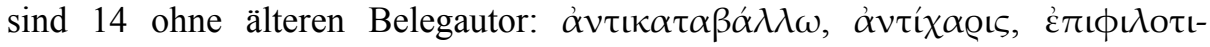

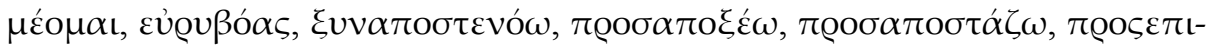

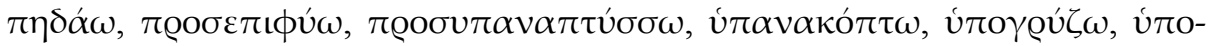
$\psi \varepsilon \lambda \lambda i \zeta \omega$ und $\phi \iota \lambda \varepsilon \lambda \varepsilon v \theta \varepsilon \dot{0} \iota_{0}$. Auch diese Liste kann nach den Tabulae erweitert

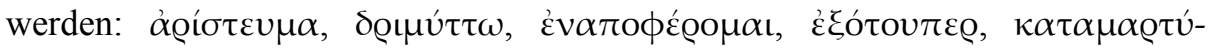

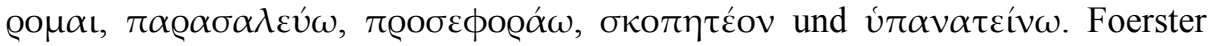
bemerkt ferner, daß [Decl.43] zwei Wörter dieser Art mit [Decl.40] gemeinsam

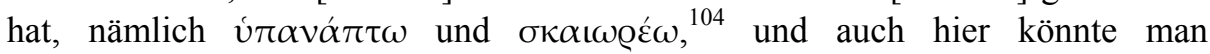

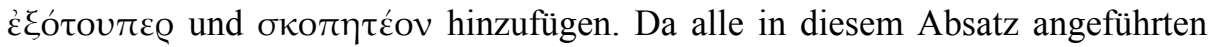
Wörter nur in [Decl.40] oder [Decl.43] vorkommen und bis in die Zeit des Libanios nicht belegt sind, ergibt sich so doch - auch nach Reduzierung bzw. Umgestaltung der Foersterschen Listen - ein weiteres starkes Argument für eine Abfassung beider Deklamationen erst nach Libanios und mit den vier gemeinsamen Wörtern auch eines für ihre Zusammengehörigkeit. Dies gilt um so mehr, als Wörter, die vor Libanios unbelegt sind, sonst ziemlich vereinzelt auftreten.

Die Erstbelege des Libanios sind im Deklamationskorpus wie folgt verteilt: ${ }^{105}$

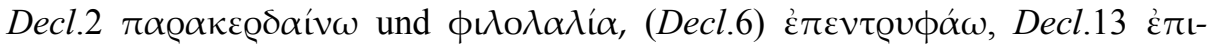

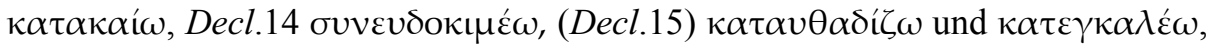

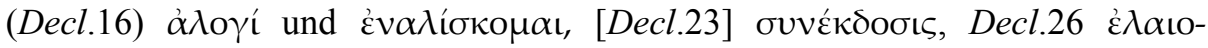

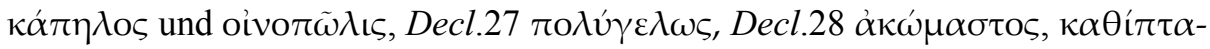

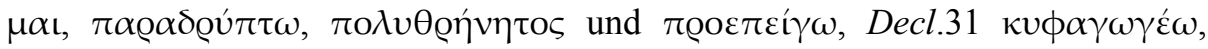

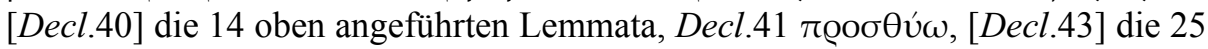

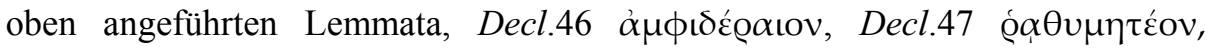

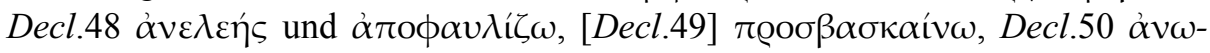

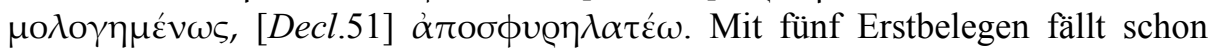
Decl.28 auf, [Decl.40] und [Decl.43] vollends scheinen ganz aus dem Rahmen zu fallen. Berücksichtigt man aber die unterschiedlichen Textlängen, ${ }^{106}$ so zeigt sich, daß Decl.28 zum selben Extrembereich gehört wie [Decl.40] und [Decl.43], denn diese haben etwa die vierfache Länge, so daß Decl.28 bei entsprechendem Umfang und prinzipiell gleichmäßiger Verteilung auf ca. 20 Erstbelege käme und damit zwischen [Decl.40] und [Decl.43] läge.

103 Libanius VII, 431f.

104 Libanius VII, 432.

105 Tabulae 2.2, 577, 597 und 605f., sowie Tabulae 2.1, 3-198, „Häufigkeitstabelle zum Vokabular der Deklamationen“.

106 Tabulae 2.1, 370, unter „Tl“. 
Die übrigen Deklamationen, mit höchstens ein oder zwei Erstbelegen, scheinen demgegenüber den Normalfall zu dokumentieren. ${ }^{107}$

\section{4 [Decl.18] und [Decl.20]}

[Decl.18], „Hyperidis oratio“, ist wie von Gasda ${ }^{108}$ so auch von Foerster dem Libanios abgesprochen worden: ${ }^{109}$ „Declamatio cum in singulis rebus et historiae et elocutionis crebrius et gravius peccat (...) tum omnino exilior atque inelegantior est quam ut a Libanio eam profectam esse credere possim." Konkret gibt Foerster - in der Klammer des Zitats - nur vier Stellen an, zwei stilistisch auffällige und zwei sprachlich anstößige (iv $\alpha$ statt $\omega \sigma \tau \varepsilon$ und $\tilde{\eta} \varsigma$ statt $\tilde{\eta} \sigma \theta \alpha$ ), außerdem aber eine - ganz gegen die Gewohnheit des Libanios - fast wörtliche Übernahme eines ganzen Satzabschnittes aus Thukydides II.41.4 ${ }^{110}$ in [Decl.18.35]. Im RE-Artikel von Foerster/Münscher ist schließlich noch eine „erhebliche Gleichgültigkeit gegen den Hiatus" angeführt. ${ }^{111}$

[Decl.20], „Demosthenis se incusantis oratio“, wurde schon von Jacobs als dürftige Nachahmung von Decl.19 und damit als unecht angesehen. ${ }^{112}$ Foerster schließt sich diesem Urteil nur teilweise an, äußert aber doch starke Zweifel an der Authentizität: ${ }^{113}$,tamen me quoque pariter atque in declamationibus II, XV, XVI cum propter universam compositionis formam tum propter singula elocutionis idiomata (ut $\pi \alpha \varrho \alpha v \tau \alpha ́$ p. 309.10) de authentia dubitandi gravissimas rationes

107 Als Erstbelegdichte ergibt sich: [Decl.43] 4.20\%, Decl.28 3.02\%o, [Decl.40] 2.02\%o, [Decl.51] 0.94\%o, Decl.2 0.69\%o, Decl.26 0.55\%o, Decl.27 0.50\%o, [Decl.29] 0.45\%o, Decl.48 0.40\%, (Decl.15) 0.38\%, Decl.14 0.34\%, (Decl.16) 0.31 \%, Decl.46 0.30\%, Decl.50 0.28\%, Decl.41 0.27\%o, Decl.31 0.25\%, Decl.47 0.24\%o, (Decl.6) 0.19\%o, Decl.13 0.18\%o, [Decl.23] 0.13\%o. Die übrigen Deklamationen enthalten keine Erstbelege und haben daher den Wert 0.00\%.

108 A. Gasda, Kritische Bemerkungen zu den Declamationen des Libanios (Zu Libanios 4), in: Evangelisches Städtisches Gymnasium zu Lauban, Jahresbericht, Lauban 1874, 1-22, besonders 11: „Hier steht iv $\alpha$ in der Bedeutung von ita ut. So hat L. nicht geschrieben und ist dies ein Grund mehr dafür, dass dieses kindische Product nicht von ihm herrührt.“

109 Libanius VI, 240, insbesondere Anm. 1.

110 Nicht 41.2 .

111 Foerster/Münscher, Sp. 2513.

112 F. Jacobs, Brevis annotatio ad quinque Libanii Declamationes, in: Allgemeine Schulzeitung 1832, Abtheilung II, Nr. 7/8, Sp. 49-64; dort Sp. 59 zu [Decl.20]: „Caeterum mihi persuasum est, ieiunam hanc declamationem non esse Libanii, sed imitatoris eius, qui genuinam Antiocheni sophistae de eodem argumento orationem, quae legitur p. 240 (Reiske, i. e. Decl.19), aemulari studuit." Derselbe, Corrections inédites, in: Revue de philologie, de littérature et d'histoire anciennes 2 (1847) 1-6 und 425-427 (von F. Dübner aus privaten Mitteilungen vorgenommene Extrakte), insbesondere 425: „Cette déclamation ... n'est pas de Libanius, mais bien d'un rhéteur qui a imité ce maitre.“

113 Libanius VI, 291. 
habere confiteor." Leider fehlen weitere Belege, und $\pi \alpha \varrho \alpha v \tau \alpha$,geradewegs“, immerhin bei Demosthenes und Euripides belegt, bietet eigentlich keinen Anstoß.

Damit sind für [Decl.18] höchstens fünf Stellen angegeben, die gegen eine Autorschaft des Libanios sprechen, und für [Decl.20] praktisch keine. Die Argumentation Foersters beruht hier also fast ganz auf den angeführten allgemeinen Qualitätsurteilen über Aufbau und Stil. Eine mögliche Zusammengehörigkeit von [Decl.18] und [Decl.20] hat Foerster nicht erwogen, was bei der geringen Zahl an konkreten Hinweisen auch nicht verwundert. Um so wichtiger ist hier das statistische Material der Tabulae. Zunächst müssen wieder die Aussagen zum Hiat relativiert bzw. korrigiert werden: [Decl.18] hat die ziemlich niedrige Hiatrate von $3.6 \%$, nur neun der 51 Deklamationen unterschreiten diesen Wert. ${ }^{114}$ Tatsächlich stellt nicht eine „Gleichgültigkeit gegen den Hiatus“, sondern gerade die niedrige Hiatrate [Decl.18] in die Nähe unechter und zweifelhafter Werke.

In den Klassifikationen nach Funktionswörtern, nach allgemeineren Inhaltswörtern und nach Wortarten treten [Decl.18] und [Decl.20] immer als Paar auf, und zwar sogar etwas enger verbunden als [Decl.40] und [Decl.43]. ${ }^{115}$ In der Hiatrate und in der mittleren Satzlänge liegen [Decl.18] und [Decl.20] dicht, im Anteil der Fragen und in der mittleren Wortlänge sehr dicht beieinander. Den statistisch untersuchten Merkmalen zufolge sollten also [Decl.18] und [Decl.20] nicht weniger einem gemeinsamen Autor zuzuschreiben sein als [Decl.40] und [Decl.43]. Daß dieser Autor wohl nicht Libanios ist, ergibt sich mit einiger Wahrscheinlichkeit aus Foersters Gesamturteilen und seinen Einzelbeobachtungen zu [Decl.18], mögen letztere auch nur wenige sein. Hinzu kommt, daß [Decl.18] und [Decl.20] bei der automatischen Klassifizierung nur selten gut in das Gros der echten Deklamationen integriert werden ${ }^{116}$ und daß sie in zwei Skalierungen einem Extrembereich zuzuordnen sind: im geringen Fragenanteil und in der großen mittleren Wortlänge. Auffällig bleibt das merklich reichere Vokabular in [Decl.20], doch liegen beide Deklamationen damit noch im Mittelfeld. ${ }^{117}$

114 Tabulae 2.1, 379, „Übersichtstabelle zum Hiat, Deklamationen“, „\%H“ unter „Einfache Wortfugen".

115 Der Unterschied ist aber gering.

116 Bei der Klassifikation nach Buchstabenverteilungen, und nur dort, wird [Decl.18] gut in das Gros eingebunden, getrennt von [Decl.20], vgl. Tabulae 2.1, 360. Bei der Klassifikation nach allgemeineren Inhaltswörtern stehen beide gemeinsam am Rande der echten Hauptfamilie, zusammen mit einigen weiteren, z.T. unechten Werken, vgl. Tabulae 2.1, 358.

117 Tabulae 2.1, 370, unter ,que/s “, ,Wl“ und ,z(Vu)“. 
Die Residuenanalyse der Wortartenverteilungen zeigt, daß [Decl.18] und [Decl.20] auffallend wenige Adverbien und beiordnende Konjunktionen haben, im Bereich der Funktionswörter treten aber keine besonders auffallenden Gemeinsamkeiten zutage: Zwar ist in beiden Deklamationen $\delta \varepsilon ́$ eher selten und ó,

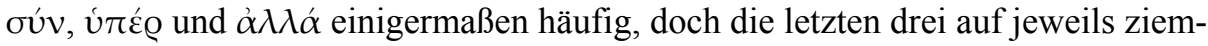
lich unterschiedlichem Signifikanzniveau. Immerhin tragen diese Gemeinsamkeiten zu den Ergebnissen der automatischen Klassifikation bei.

\section{5 [Decl.51] und Decl.28}

[Decl.51] und Decl.28 unterscheiden sich, wie die Tabellen in Abschnitt 4.1 zeigen, ebensowenig, ja fast weniger als die zuvor besprochenen Paare $\{($ Decl.15),(Decl.16)\}, $\{[$ Decl.40],[Decl.43]\} und $\{[$ Decl.18],[Decl.20]\}. Die Hauptabweichungen voneinander liegen im Anteil der Fragen und in der mittleren Satzlänge, doch dies kann mit dem Gattungsunterschied erklärt werden: Die Monodie [Decl.51] hat einen höheren Fragenanteil (26\% gegenüber 19\%) und im Mittel kürzere Sätze (14.3 Wörter gegenüber 17.8), Züge, die aus dem Redenkorpus des Libanios hinreichend bekannt sind. ${ }^{118}$

$\mathrm{Zu}$ der Frage, ob Decl.28 auch als unecht oder [Decl.51] doch als echt anzusehen ist, muß angemerkt werden, daß schon beide Positionen vertreten worden sind: August Gasda hat Decl.28 dem Libanios abgesprochen, ${ }^{119}$ und zwar vor allem aufgrund inhaltlicher Anstöße, genauer mythologischer Verwechslungen, die aber, worauf Foerster zu Recht verweist, ${ }^{120}$ durchaus dazu dienen können, den Sprecher als halbgebildeten Parasiten zu charakterisieren. Andererseits ist die Echtheit von [Decl.51] von früher mit dieser Monodie befaßten Philologen nicht angezweifelt worden, so von Boissonade als Herausgeber, von Kock, der [Decl.51] als Quelle für die attische Komödie verwendete, und von Salzmann, der Sprichwörter und sprichwörtliche Redensarten bei Libanios untersucht hat. ${ }^{121}$ Foerster begründet den Ausschluß von [Decl.51] zum einen mit seinem Gesamturteil über Stil und Anlage, ${ }^{122}$ zum andern aber mit einer Liste von 17 Wörtern,

118 Sprachstatistische Untersuchungen 1, 132 (Anteil der Fragen) und 137 (Satzlänge), vor allem die Monodien Or.60 und Or.61.

119 Gasda, Kritische Bemerkungen (s. Anm. 108), 4.

120 Libanius VI, 565, Anm. 2.

121 J. F. Boissonade, Anecdota Graeca I, Paris 1829 (Nachdruck Hildesheim 1962), 165-171; Th. Kock, Comicorum Atticorum Fragmenta III, Leipzig 1888, 667/68 (Nr. 1507-1510); E. Salzmann, Sprichwörter und sprichwörtliche Redensarten bei Libanios, Diss. Tübingen 1910. Alle von Foerster in der Praefatio erwähnt.

122 Libanius VII, 727: „diversitas dictionis et tractationis, quam illo (i.e. Libanio) multo inferiorem iudicare non dubito." 
die er dem Libanios absprechen möchte. ${ }^{123}$ Alle diese Wörter treten, wie man den Tabulae entnehmen kann, ${ }^{124}$ im Corpus Libanianum tatsächlich nur einmal, also nur in dieser Monodie auf, aber dieser Umstand besagt, wie schon erwähnt, ziemlich wenig, da es im Gesamtkorpus sehr viele Wörter gibt, die genau einmal auftreten. ${ }^{125}$ Es ist also eher danach zu fragen, ob die betreffenden Lemmata bei Belegautoren $\mathrm{zu}$ finden sind, die dem Libanios als Fundgrube gedient haben könnten. Dazu die folgende Übersicht über die 17 Lemmata und ihre Belegauto-

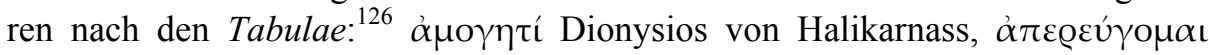

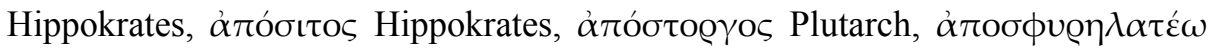

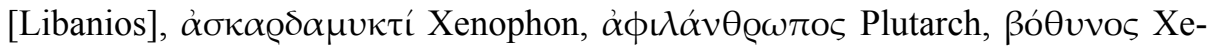

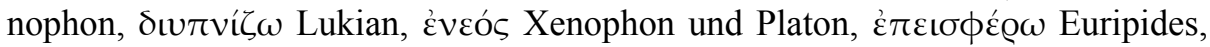

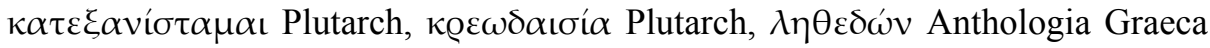

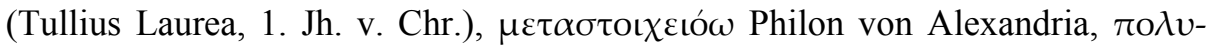
$\pi \lambda \alpha ́ \sigma ı \varsigma$ Isokrates und $v \pi \varepsilon \xi \alpha v i ́ \sigma \tau \alpha \mu \alpha \iota$ Lukian. Neben klassischen attischen Autoren wie Isokrates, Xenophon, Platon und Euripides sind also vor allem Attizisten und Halbattizisten vertreten (Dionysios von Halikarnass, Lukian, Plutarch), daneben der ionische Autor Hippokrates, ferner Philon als Vertreter einer Koine mit attischen Elementen, sowie schließlich als Sonderfälle Tullius Laurea ${ }^{127}$ und Libanios selbst. In meiner Prioritätenliste der Belegautoren haben Hippokrates, Dionysios von Halikarnass, Lukian, Plutarch und Philon (in dieser Reihenfolge) mittlere Positionen inne, ${ }^{128}$ doch ist dazu zu bemerken, daß eben diese Autoren als Belegautoren für die - echten - Briefe und Reden stark unterrepräsentiert sind, bei den unechten Deklamationen und z.T. auch den unechten Progymnasmata aber stark überrepräsentiert, dies alles mit hoch signifikanten Abweichungen von einem Anteil, der den Teilkorpusumfängen entspräche. ${ }^{129}$ Man sieht also, daß Libanios auf diese Autoren erheblich seltener zurückgegriffen hat als die Verfasser der unechten Deklamationen und Progymnasmata. Dennoch stehen Hippokrates, Dionysios von Halikarnass, Lukian, Plutarch und Philon durchaus für einige Lemmata der Reden und der echten Deklamationen, ${ }^{130}$ und gerade die echten Deklamationen zeigen in dieser Hinsicht keine signifikante Unterschreitung der

123 Libanius VII, 727: „usus vocabulorum ab illo (i.e. Libanio) alienorum“.

124 Tabulae 2.2, 403-574, „Häufigkeitstabelle zum Gesamtvokabular, mit Belegautoren“.

$125 \mathrm{Vgl}$. Abschnitt 1.1 und 4.3.

126 Tabulae 2.2, 403-574, „Häufigkeitstabelle zum Gesamtvokabular, mit Belegautoren“.

127 Tullius Laurea war ein Freigelassener Ciceros.

128 Tabulae 2.2, IX.

129 Tabulae 2.2, 754f., „Zusammenfassung nach Belegautoren, Binomialtests“.

130 Tabulae 2.2, 751f., „Zusammenfassung nach Belegautoren, Häufigkeiten im Gesamtkorpus“. Hippokrates: 15mal Or., 15mal Decl.; Dionysios von Halikarnass: 6mal Or., 6mal Decl.; Lukian: 47mal Or., 95mal Decl.; Plutarch: 15mal Or., 31mal Decl.; Philon: 6mal Decl. Diese Häufigkeiten beziehen sich auf die Vorkommen, nicht auf die im allgemeinen etwas geringere Anzahl der Lemmata, und zwar die Vorkommen in den echten Schriften. 
statistischen Erwartung, ${ }^{131}$ vielmehr überschreiten sie diese Erwartung ein wenig bei Hippokrates und Philon, und bei Lukian sogar in sehr hohem Maße. Damit dürfte klar sein, daß diese fünf Belegautoren nicht gegen die Autorschaft des Libanios sprechen. Weniger deutlich ist dies für den Beleg aus der Anthologia Graeca 7.17 (Tullius Laurea), doch kommen solche Sonderfälle immer wieder auch in den echten Werken vor, gerade bei den mit nur einem einzigen Wort vertretenen Belegautoren. Für die echten Deklamationen etwa wären die folgenden zu nennen: Agatharchides, Archimedes, Aretaios, Cornutus, Diogenes von Sinope, Ephippos, Plotin, Pseudo-Kallisthenes und Symmachos. ${ }^{132}$ Problematisch bleibt daher vor allem das eine Wort $\alpha \pi \operatorname{ro\sigma } \phi v \varrho \eta \lambda \alpha \tau \dot{\varepsilon} \omega$, das bis hin zu Libanios nicht belegt ist. Selbst das Simplex $\sigma \phi v \emptyset \eta \lambda \alpha \tau \varepsilon \dot{\omega} \omega$ kommt nur bei Philon von

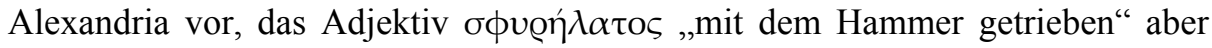
bei Aischylos, Herodot, Platon und anderen, insbesondere auch in einem Leosthenes-Zitat (4. Jh. v.Chr.) aus dem Pseudo-Lukianischen Enkomion auf Demosthenes ${ }^{133}$ und mehrmals bei Plutarch, dabei zweimal in der Verbindung

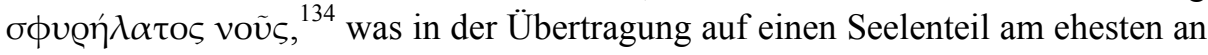

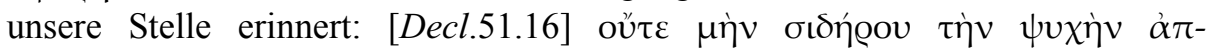

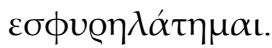

$\mathrm{Da}$ das Verb $\sigma \phi v \varrho \eta \lambda \alpha \tau \varepsilon ́ \omega$ erst spät und äußerst spärlich belegt ist, verwun-

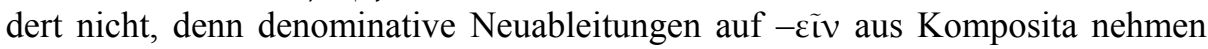
zwar in klassischer und besonders nachklassischer Zeit gegenüber den Neuableitungen aus Simplicia wie auch absolut stark zu, doch wurde nur selten und offenbar erst in nachklassischer Zeit zu einem passivischen Grundwort wie $\sigma \phi v \varrho \eta ́ \lambda \alpha \tau o \varsigma$ ein faktitives Verbum wie $\sigma \phi v \varrho \eta \lambda \alpha \tau \dot{\varepsilon} \omega$ gebildet. ${ }^{135}$ Außerdem ist der durch das Verb bezeichnete handwerkliche Vorgang, ,mit dem Hammer treiben“, offenbar von geringerem Interesse gewesen als die Resultate dieses Tuns, handgeschmiedete Geräte und Bildwerke etwa, die sich durch zähe Festigkeit und besondere Oberflächenstruktur auszeichnen. Es ist deshalb gut möglich, daß das Verb $\sigma \phi v @ \eta \lambda \alpha \tau \varepsilon \dot{\epsilon} \omega$ schon in hellenistischer Zeit in der Alltagssprache verwendet wurde, obwohl erst Philon einen literarischen Beleg liefert. Libanios könnte durch die klassischen Belege des Adjektivs wie durch seine Verwendung in übertrage-

131 Tabulae 2.2, 754f., „Zusammenfassung nach Belegautoren, Binomialtests“.

132 Tabulae 2.2, 751f., „Zusammenfassung nach Belegautoren, Häufigkeiten im Gesamtkorpus“.

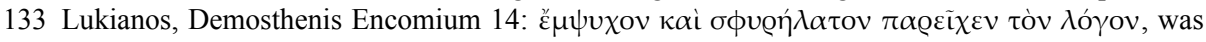
hier wohl auf den Vergleich mit Bildwerken abzielt.

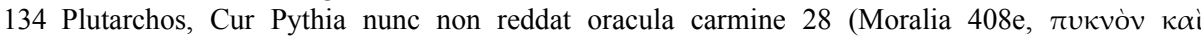

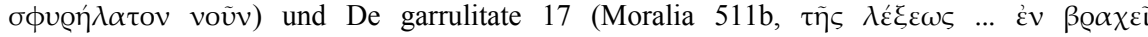

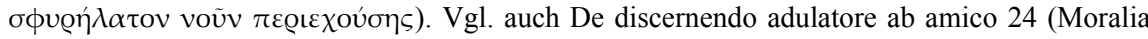

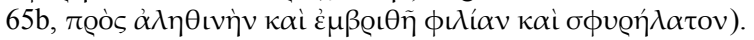

135 A. Debrunner, Griechische Wortbildungslehre, Heidelberg 1917, 95 und 97, mit den Beispielen $\dot{\alpha} \theta \varepsilon \tau \varepsilon \tilde{\varepsilon} v$ und $\varepsilon \dot{v} \theta \varepsilon \tau \varepsilon \tilde{i} v$. 
ner Bedeutung bei Plutarch und Pseudo-Lukian angeregt worden sein, das Kompositum $\dot{\alpha} \pi \circ \sigma \phi v \varrho \eta \lambda \alpha \tau \varepsilon \dot{\epsilon} \omega$ zu bilden und in ähnlich bildhafter Weise zu verwenden. Diese Möglichkeit gewinnt dadurch an Wahrscheinlichkeit, daß Philon, Lukian und besonders Plutarch ohnehin zu den Belegautoren der oben aufgeführten seltenen Wörter von [Decl.51] gehören. Zwar ist zu bedenken, daß auffallend viele der Lemmata, die bis in die Zeit des Libanios unbelegt sind, in den unechten Schriften erscheinen, vor allem in [Decl.40], [Decl.43] und [Prog.12.30], doch gibt es durchaus auch Erstbelege in den echten Schriften des Libanios, insgesamt immerhin 57 Lemmata, zu denen auch 25 Verba composita mit präpositionalem

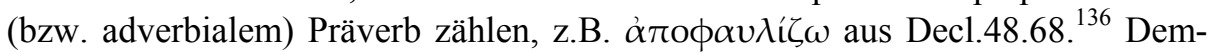

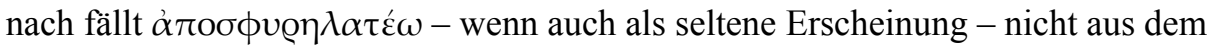
Rahmen dessen, was bei Libanios zu erwarten ist.

Insgesamt haben sich damit Foersters Einzelbeobachtungen zur Unechtheit von [Decl.51] als nicht stringent erwiesen. Umgekehrt steht [Decl.51], wie die statistischen Ergebnisse zeigen, vielfach in enger Verbindung zu Decl.28, einem vermutlich authentischen Werk: Die hohe Erstbelegdichte in Decl.28 - die zweithöchste im ganzen Deklamationskorpus - ist zwar eine schwere Hypothek, dies bleibt aber, neben einer niedrigen Hiatrate, der einzige Punkt, in dem Decl.28 eine Sonderposition einnimmt. In den automatischen Klassifikationen ist das Paar $\{[$ Decl.51],Decl.28\} immer ziemlich gut in die große Familie der echten Deklamationen eingebunden. ${ }^{137}$ Im Vokabularreichtum steht [Decl.51] sogar an der Spitze der Deklamationen - in der Nachbarschaft nur echter Werke. Ich halte es daher für einigermaßen wahrscheinlich, daß [Decl.51] doch zu den authentischen Werken des Libanios gehört. Daß auch zwei authentische Deklamationen ein besonderes Paar bilden können, könnte das Beispiel von $\{$ Decl.24,Decl.25 $\}$ zeigen - vorausgesetzt daß diese beiden Werke authentisch sind. Im Falle von $\{[$ Decl.51], Decl.28\} mag eine gewisse Verwandtschaft im Thema und besonders im Charakter der Sprecher für die stilistische Ähnlichkeit verantwortlich sein: In [Decl.51] klagt ein Geizhals über den Verlust seines von Dieben geraubten Schatzes, ${ }^{138}$ in Decl.28 bittet ein Parasit um den Tod, weil er durch einen merkwürdigen Zufall um ein Mahl gekommen ist, zu welchem er eingeladen war. ${ }^{139}$

136 Tabulae 2.2, 597f., unter „Binomialtests zum Gesamtvokabular, sortiert nach Belegautoren“. Ein weiteres erst bei Libanios belegtes Kompositum mit $\alpha \dot{\pi}$ - ist $\alpha \dot{\pi}$ ó $\pi$ hot $\alpha$ aus Prog.11.4.1.

137 Tabulae 2.1, 357-360. In der Klassifikation nach Buchstabenverteilungen steht das Paar eher am Rand der großen Familie, aber doch noch nicht außerhalb. Bei den Wortarten erscheinen [Decl.51] und Decl.28 nicht als Paar, aber in benachbarten Kleingruppen überwiegend echter Deklamationen.

138 [Decl. 51] „Avari thesauro privati lamentatio“.

139 Decl.28 „Parasiti cena fraudati oratio“. Das von dem Parasiten verwendete Pferd hält den Hofaltar des Gastgebers für eine Wendemarke auf der Rennbahn und trägt den Parasiten wieder davon. 


\subsection{Decl.24 und Decl.25}

H. v. Rohden und P. Maas haben Decl.24 und Decl.25 dem Libanios abgesprochen, und zwar aufgrund strenger Hiatvermeidung und akzentuierender Satzklauseln, ${ }^{140}$ Foerster hat dies aber als unzureichende Begründung angesehen. ${ }^{141}$ Decl.24 und Decl.25 haben die niedrigsten Hiatraten aller Deklamationen, in der Nachbarschaft nur unechter und zweifelhafter Werke, doch könnte die Hiatvermeidung, wie oben bemerkt, ${ }^{142}$ Libanios als Mittel der Charakterdarstellung gedient haben. Außerdem aber gehören Decl.24 und Decl.25 zu den Deklamationen mit besonders großer mittlerer Wortlänge, und zwar ebenfalls in der Nachbarschaft lauter unechter Werke. Auch der geringe Fragenanteil stellt Decl.25 an die Seite überwiegend unechter Deklamationen und Decl.24 immerhin noch in die Nähe der zweifelhaften. Ob all dies noch mit Ethopoeie erklärt werden kann, erscheint ziemlich fraglich. Hinzu kommt eine ambivalente Stellung der beiden Deklamationen in den Dendrogrammen. In der automatischen Klassifikation nach Funktionswörtern nehmen Decl.24 und Decl.25, als Paar verbunden, zusammen mit (Decl.6) eine Position am Rande der Hauptfamilie echter Deklamationen ein, ähnlich wie die zu einer Vierergruppe verbundenen Paare $\{[$ Decl.34],[Decl.45]\} und $\{[$ Decl.18],[Decl.20]\}. Auch in der Klassifikation nach allgemeineren Inhaltswörtern steht das Paar $\{$ Decl.24,Decl.25 $\}$ am Rande der Hauptgruppe überwiegend echter Werke. Diese Randstellungen sind schwer zu interpretieren. Insgesamt - bei den Verteilungsvergleichen wie den Skalierungen - scheint die Trennung von echten und unechten Werken klarer zu werden, wenn man Decl.24 und Decl.25 zu den letzteren rechnet. ${ }^{143}$

\section{7 [Decl.23] und Decl.2}

An der Echtheit von Decl.2 hat Foerster stärker gezweifelt, als es im RE-Artikel von Foerster/Münscher zum Ausdruck kommt. Dort heißt es, mit Verweis auf Markowski: ${ }^{144}$ „Stilistisch weicht sie von der Apologie nicht unerheblich ab, darf aber als ein durch diese überholtes Jugenderzeugnis angesehen werden“. Foerster hatte sich zunächst vorsichtiger, aber doch ähnlich geäußert: ${ }^{145}$ „Et quamquam in

140 S. Anm. 46 und Anm. 47.

141 Libanius VII, 641, Anm. 1.

142 Vgl. Abschnitt 2.3.

143 Decl.25 bleibt auch in der Klassifikation nach Buchstabenverteilungen sehr isoliert.

144 Foerster/Münscher, Sp. 2510. H. Markowski, De Libanio Socratis defensore (Breslauer Philologische Abhandlungen 40), Breslau 1910 (Nachdruck Hildesheim 1970), 172-178 („De ratione, quae intercedit inter decl. II et Libanii apologiam Socratis").

145 Libanius V, 123, Anm. 1. 
dictione imprimisque verborum collocatione nonnulla sunt insolita quae dubitationes de authentia declamationis moveant, tamen eam a Libanio praesertim adulescente scribi potuisse negare nolo." Später, in der Praefatio zu [Decl.20], läßt er aber stärkere Zweifel durchblicken: ${ }^{146}, \ldots$ tamen me quoque pariter atque in declamationibus II, XV, XVI cum propter universam compositionis formam tum propter singula elocutionis idiomata ... de authentia dubitandi gravissimas rationes habere confiteor."

In zwei der vier Klassifikationen treten [Decl.23] und Decl.2 zu einem eher locker verbundenen Paar zusammen. Dabei nimmt \{[Decl.23],Decl.2\} in der Klassifikation nach allgemeineren Inhaltswörtern eine ähnlich isolierte Position ein wie $\{[$ Decl.34],[Decl.45]\}, $\{($ Decl.15),(Decl.16)\}, $\{[$ Decl.40],[Decl.43]\}, (Decl.6) und [Decl.49]. In der Klassifikation nach Wortarten hebt sich das Paar sogar ziemlich deutlich vom Rest der ethologischen Deklamationen und damit von allen anderen Deklamationen überhaupt ab, wobei beide wiederum nur locker miteinander verbunden sind, weniger eng als alle anderen Paare. [Decl.23] und Decl.2 sind also in keiner dieser beiden Klassifikationen in das Gros des echten Korpusteils integriert. In der Klassifikation nach Funktionswörtern ist Decl.2 locker mit Decl.13 verbunden, und auch diese beiden stehen dort eher am Rande des Korpus. Schließlich bleibt Decl.2 in der Klassifikation nach Buchstabenverteilungen ganz isoliert, fast ebenso wie [Decl.49],[Decl.23] und [Decl.43] und deutlich stärker als [Decl.40], Decl.25 und [Decl.34]. ${ }^{147}$ Decl.2 tritt also, was den Isolationsgrad in der Buchstabenverteilung angeht, zur Spitzengruppe der unechten Deklamationen. So wird durch alle vier Klassifikationen die Außenseiterposition von Decl.2 bezeugt, und zwar in einem Maße, das für unechte Deklamationen charakteristisch ist, außerdem aber eine gewisse Nähe zu [Decl.23]. ${ }^{148}$

Deutlicher tritt diese Nähe in den eindimensionalen Skalierungen hervor: Immerhin drei von fünf Merkmalen - Vokabularreichtum, mittlere Wortlänge und Fragenanteil - zeigen Decl.2 und [Decl.23] in enger bis engster Nachbarschaft. $\mathrm{Ob}$ das hinreicht, um beide ein und demselben Verfasser zuzuweisen, ist schwer $\mathrm{zu}$ entscheiden, in jedem Falle werden aber durch die so deutlicher hervortretende Bindung von Decl.2 an eine doch sicherlich unechte Deklamation die Zweifel an der Echtheit von Decl.2 verstärkt.

Die Unechtheit von [Decl.23] begründet Foerster mit einigen auffälligen rhetorischen Häufungen, historischen Irrtümern und vor allem einer Reihe von Ver-

146 Libanius VI, 291.

147 Der Isolationsgrad läßt sich an der Länge der waagerechten Äste im Dendrogramm ablesen. Er nimmt für die genannten Deklamationen folgende Werte an: [Decl.49]: 100, [Decl.23]: 87, [Decl.43]: 87, Decl.2: 84, [Decl.40]: 68, Decl.25: 67, [Decl.34]: 59.

148 Die Nähe zu [Decl.23] ist in den Klassifikationen eigentlich eher gering, aber immerhin doch größer als zu allen anderen Deklamationen. 
stößen gegen den attischen Sprachgebrauch. ${ }^{149}$ Einen weiteren Hauptgrund sieht

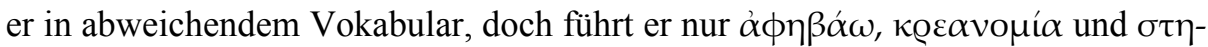
$\lambda ı \tau \varepsilon v ́ \omega$ an, die mit den Belegautoren Philon, Theopomp und Plutarch eigentlich keinen sonderlichen Anstoß bieten, ebenso wie eine von Foerster vermutete Plutarch-Reminiszenz. Nach der Gesamtzahl der Lemmata, die Plutarch zum Belegautor haben, stehen nämlich vor Plutarch (77 Lemmata) nur Aristophanes (293 Lemmata), Euripides (178 Lemmata), Aristoteles (144 Lemmata) und Lukian (78 Lemmata), so daß eine gewisse Bekanntschaft mit Werken des Plutarch nicht unwahrscheinlich ist, auch wenn ein überproportionaler Anteil der Vorkommen von Plutarch-Lemmata auf die unechten Deklamationen und Progymnasmata entfällt. ${ }^{150}$ Das ist nämlich bei Aristoteles und Euripides ähnlich, z.T. auch bei Aristophanes (in den unechten Progymnasmata überrepräsentiert) und Lukian (in den unechten Deklamationen überrepräsentiert). ${ }^{151}$ Auch die echten Werke des Libanios enthalten nicht wenige Lemmata dieser Belegautoren.

Foersters Zweifel an der Authentizität von [Decl.23], vielleicht bestärkt durch Tycho Mommsen, ${ }^{152}$ werden, aufs Ganze gesehen, durch die statistischen Beobachtungen bestätigt. Die eindimensionalen Merkmale lassen kaum Besonderheiten erkennen: [Decl.23] hat zwar im Mittel die kürzesten Fragen, liegt damit aber noch in der Nähe von Decl.12 und Decl.26. Die Verteilungsvergleiche dagegen weisen eindeutig auf eine Sonderrolle: In der Verteilung der Funktionswörter hat [Decl.23] die zweitgrößte Gesamtabweichung vom Korpusdurchschnitt, ${ }^{153}$ in Wortarten- und Buchstabenverteilung sogar die größte. Die Gesamtabweichung in der Verteilung der allgemeineren Inhaltswörter fällt zwar weniger extrem aus, stellt [Decl.23] aber immerhin zur Spitzengruppe überwiegend unechter Deklamationen. So nimmt [Decl.23] in allen vier Klassifikationen Außenseiterpositionen ein, z.T. in lockerer Verbindung mit Decl.2. Auch Decl.2 fällt (s. o. in diesem Abschnitt), vor allem durch Außenseiterpositionen in den Klassifikationen auf. ${ }^{154}$

149 Libanius VI, 370f.: „Et revera declamatio cum universa compositionis forma imprimisque nimia, paene dixerim, putida rerum abundantia (Häufung) a genuinis differt tum tot res (Sachirrtümer) et locutiones (unkorrekte Ausdrucksweise) imprimisque voces a Libanio alienas (abweichendes Vokabular) exhibet, ut, nisi eam aetati iuvenili tribuere vis, satis causae sit cur de authentia dubites." Dazu Foersters Anm. 2-4 ebendort.

150 Tabulae 2.2, 751f. „Zusammenfassung nach Belegautoren, Häufigkeiten im Gesamtkorpus“. Die hohen Zahlen bei Aristoteles und Plutarch sind z.T. auch mit dem großen Umfang ihrer Werke zu erklären.

151 Tabulae 2.2, 754f.

152 T. Mommsen, Beiträge zur Lehre von den griechischen Präpositionen, Berlin 1895 (2. Aufl. Hildesheim 2004), 503, Anm. 3.

153 [Decl.23] hat im Bereich der Funktionswörter die zweitgrößte Anzahl hoch signifikanter und die größte Anzahl extrem signifikanter Einzelabweichungen.

154 In den Praefationes zu Decl.2 und [Decl.23] erwägt Foerster die Möglichkeit, diese Werke, wenn sie denn authentisch sein sollten, als Jugendschriften des Libanios zu akzeptieren, er bringt sie aber nicht miteinander in Verbindung. 


\section{8 [Decl.34] und [Decl.45]}

In den linearen Skalierungen sind [Decl.34] und [Decl.45] meist deutlich getrennt, nur in der Hiatrate sind sie einander sehr ähnlich. Hier liegen sie im Mittelfeld. Die automatischen Klassifikationen führen [Decl.34] und [Decl.45] zweimal zu einem Paar zusammen, einmal aufgrund der Funktionswörter und einmal aufgrund der allgemeineren Inhaltswörter. Im letzten Fall allerdings zeigt das Paar $\{[$ Decl.34],[Decl.45]\} nach $\{$ Decl.12,Decl.13\} die größte innere Unähnlichkeit, [Decl.34] und [Decl.45] sind nur etwa ebenso locker aneinander gebunden wie einige der isoliertesten Deklamationen an das Korpus, selbst [Decl.23] und Decl.2 sind etwas enger verbunden. ${ }^{155}$ Nur bei den Funktionswörtern bilden [Decl.34] und [Decl.45] ein etwas enger geschlossenes Paar, in Nachbarschaft übrigens zu $\{[$ Decl.18],[Decl.20]\}. Diese Vierergruppe unechter Deklamationen ist am Rande der echten Hauptfamilie angesiedelt, doch steht die Gruppe der drei epideiktischen Deklamationen, $\{\{$ Decl.3,Decl. 4$\}$, Decl. .5$\}$, noch etwas weiter außen, offenbar aufgrund der besonderen literarischen Gattung. ${ }^{156}$ Festzuhalten ist, daß nur zwei der neun Merkmale [Decl.34] und [Decl.45] in wirklicher Nachbarschaft zeigen. ${ }^{157}$

Die Residuen zeigen, daß unter den allgemeineren Inhaltswörtern $\pi 0 \lambda v ́ \varsigma$ und

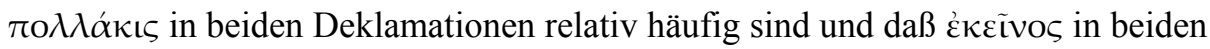
eher selten ist (all dies in [Decl.45] etwas ausgeprägter). Doch treten auch charakteristische Unterschiede hervor: $\theta \varepsilon o ́ \varsigma$ ist in [Decl.34] sehr häufig, häufig auch

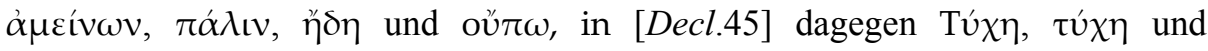

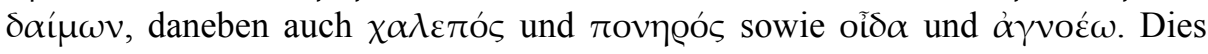
erklärt zu einem guten Teil die nur sehr lockere Verbindung von [Decl.34] und [Decl.45] in der automatischen Klassifikation nach allgemeineren Inhaltswörtern. Unter den Funktionswörtern sind - um einmal von $\dot{\varepsilon} \gamma \omega \dot{\omega}$ abzusehen, das in den meisten ethologischen Deklamationen überrepräsentiert ist - in beiden Deklama-

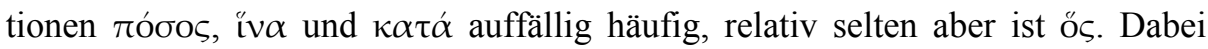

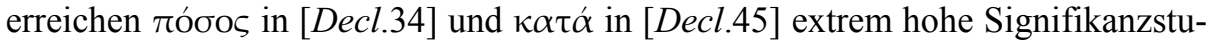
fen. ${ }^{158}$ Die besondere Häufigkeit von ív $\alpha$ teilen beide mit [Decl.20], aber auch mit dem echten Werk Decl.27. ${ }^{159}$ Deutlicher ist die besondere Häufigkeit von

155 Tabulae 2.1,358.

156 Tabulae 2.1, 357. Einzelne echte Deklamationen stehen noch weiter außen.

157 H. v. Rohden (s. Anm. 46), 41, Anm. 16, vermutet - gestützt vor allem auf seine Beobachtungen zum Hiat - eine engere Zusammengehörigkeit von [Decl.34] und [Decl.45]: ,unius ni fallor scriptoris sunt, sed qui praeceptum (scil. de hiatu) aliquanto licentius observavit." Tatsächlich stehen [Decl.34] und [Decl.45] mit Hiatraten von 4.3\% bzw. 4.4\% schon außerhalb des Extrembereichs.

158 Tabulae 2.1, 303 und 299.

159 Außerdem, etwas weniger signifikant, auch mit Decl.24 und Decl.32. 
$\kappa \alpha \tau \alpha ́$ mit unechten Deklamationen verbunden, sie zeigt sich mit höchster Signifikanz in [Decl.45] und [Decl.49], mit hoher in [Decl.29], [Decl.34] und Decl.37, mit mittlerer in (Decl.6) und (Decl.15) sowie mit schwacher in [Decl.18] und Decl.38. ${ }^{160}$ Dies alles spricht weniger für eine besondere Zusammengehörigkeit von [Decl.34] und [Decl.45] als für ihre Unechtheit.

Foerster begründet die Unechtheit der beiden Deklamationen jeweils mit einer Liste von Verstößen gegen den attischen Sprachgebrauch, auch mit einzelnen Vokabeln, besonders aber mit negativen Gesamturteilen. $\mathrm{Zu}$ [Decl.34] schreibt er: ${ }^{161}$ „Desiderantur gratia, festivitas, sollertia, varietas sermonis. Comparet sterilitas, ariditas, inertia, inopia. Crebrae sunt repetitiones et vocabulorum et sententiarum, crebrae non minus polysyndeta quam asyndeta ... Desideratur studium scriptorum veterum quos Libanius suum in usum convertit, imprimis comicorum, Demosthenis, Platonis.“ $\mathrm{Zu}$ [Decl.45]: ${ }^{162}$ „Nam ab illa arte (Libanii) prorsus abhorret cum exilitate totius argumenti tum inopia atque ieiunitate tractationis." Foerster merkt auch an, daß schon Gasda [Decl.45] zu Recht als ,schwächliches Produkt aus späterer Zeit“ bezeichnet habe. ${ }^{163}$ Tatsächlich rechfertigen m.E. schon die sprachlichen Anstöße ein solches Urteil. Die von Foerster dem Libanios abgesprochenen Vokabeln dagegen könnten, wie die Belegautoren der Tabulae

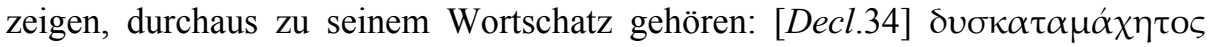

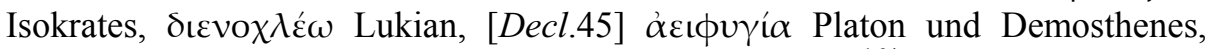

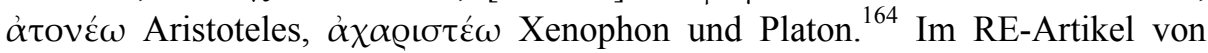
Foerster/Münscher ist schließlich vermerkt, daß die strikte Beobachtung akzentuierender Satzschlüsse in [Decl.45] auf eine Schülerarbeit aus späterer Zeit deutet und daß erst Johannes Doxapatres (11. Jh.) diese Deklamation als Werk des Libanios kennt. ${ }^{165}$

Aus statistischer Sicht sprechen schon die automatischen Klassifikationen gegen die Authentizität von [Decl.34] und [Decl.45]: In der Klassifikation nach Funktionswörtern bildet das Paar $\{[$ Decl.34],[Decl.45]\} zusammen mit dem Paar $\{[$ Decl.18],[Decl.20]\} eine Vierergruppe unechter Deklamationen die am Rand der echten Hauptfamilie liegt, vor allem aber bringen die allgemeineren Inhaltswörter [Decl.34] und [Decl.45] in die Nachbarschaft lauter unechter und zweifelhafter Werke: [Decl.49], \{[Decl.40],[Decl.43]\}, (Decl.6), $\{($ Decl.15), (Decl.16) $\}$, $\left\{\left[\right.\right.$ Decl.34],[Decl.45]\}, \{Decl.2, [Decl.23]\}. ${ }^{166}$ Ferner nehmen [Decl.34] und

160 Die zugehörigen Residuen sind (in der oben gegebenen Reihenfolge): 8.7, 7.5, 4.1, 4.1, 3.9, 3.8, 3.4, 2.0 und 2.3. Vgl. Tabulae 2.1, 297 und 299.

161 Libanius VII, 110, Anm. 1.

162 Libanius VII, 522.

163 Libanius VII, 522, Anm. 1, mit Verweis auf Gasda, Kritische Bemerkungen (s. Anm. 108), 20.

164 Tabulae 2.2, 403-674 „Häufigkeitstabelle zum Gesamtvokabular, mit Belegautoren“.

165 Foerster/Münscher, Sp. 2517.

166 Tabulae 2.1, 357 und 358. 
[Decl.45] in den eindimensionalen Skalierungen mehrfach Außenseiterpositionen ein: [Decl.34] hat die kürzesten Sätze des Korpus, steht hinsichtlich der allgemei-

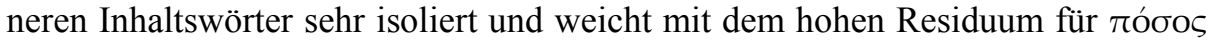
in extremer Weise vom Korpusdurchschnitt ab. [Decl.45] hat ziemlich lange Wörter, steht hinsichtlich der allgemeineren Inhaltswörter ebenfalls sehr isoliert, ${ }^{167}$ weist bei diesen eine Häufung hoch signifikanter Residuen auf ${ }^{168}$ und überschreitet insbesondere mit dem Residuum für $\kappa \alpha \tau \alpha$ den Durchschnitt in extremem Ausmaß.

\section{Drei alleinstehende Deklamationen}

\section{$5.1($ Decl.6)}

Hermann v. Rohden und Paul Maas haben die Authentizität von (Decl.6) in Frage gestellt, und zwar aufgrund von Beobachtungen zur Hiatvermeidung und zur Rhythmik der Satzschlüsse, ${ }^{169}$ Foerster hat diese Begründung aber als unzureichend angesehen, in der Meinung, daß Libanios in diesen Dingen nicht einheitlich verfahre: ${ }^{170}$ „multiplex illa atque in diversis scriptis diversa cum universa rhythmopoeia tum in clausulis pangendis ars qua splendet Libanius peculiarem postulat disquisitionem." Die auffällig niedrige Hiatrate von (Decl.6) ist allein wohl wirklich kein hinreichendes Argument gegen die Authentizität, zumal die noch strengere Hiatvermeidung in Decl.24 und Decl.25 möglicherweise mit der Absicht des Libanios zu erklären ist, die beiden Sprecher zu charakterisieren. Nun kommen aber noch zwei weitere Argumente statistischer Art hinzu: (Decl.6) hat nach [Decl.49] das zweitärmste Vokabular des Korpus, mit merklichem Abstand zu [Decl.40] und Decl.44, die an dritter und vierter Stelle folgen, und (Decl.6) steht im Bereich der allgemeineren Inhaltswörter ziemlich isoliert, in ähnlicher

167 Bei den allgemeineren Inhaltswörtern gehören [Decl.34] und [Decl.45] in der Gesamtabweichung vom Korpusdurchschnitt zur Spitzengruppe überwiegend unechter Werke.

168 Ähnliche Häufungen aber auch in [Decl.40], Decl.32 und Decl.12.

169 S. Anm. 46 und Anm. 47. M. Heitmann, De clausulis Libanianis, Diss. Münster 1912, 7, Anm. 1, bemerkt zu (Decl.6): „Quam declamationem, cum lege Meyeriana severius observata ab aliis differat, a Libanio esse abiudicandam P. Maas suspicatus est. Sed si quas proponam tabulas inspexeris, auctorem Orestis defensionis syllabarum quantitate observata eundem clausularum usum esse secutum ac Libanium mihi assentieris.“ Da Heitmann quantitierende Klauseln im Blick hat, Maas aber akzentuierende, bleiben die Bedenken des letzteren unberührt.

170 Libanius VII, 641, Anm. 1. Zur Unechtheit von [Decl.49] schreibt Foerster dort: „At hiatus fuga quam in ea repperit (v. Rohden) ad hoc statuendum non magis sufficit quam legis Meyerianae observatio qua Paulus Maas nititur." Im folgenden geht er dann in diesem Zusammenhang auch auf (Decl.6), Decl.24 und Decl.25 ein: ,eandem observationem ... et in Orestis, Archidami, Laidis declamationibus ..., quas genuinas esse omnibus praeter ipsum (Maas) Rohdenumque constat, agnovit.“ 
Position wie [Decl.49], $\{[$ Decl.40],[Decl.43]\}, $\{($ Decl.15),(Decl.16) $\}$, $\{[$ Decl.34],[Decl.45]\}, \{Decl.2,[Decl.23]\}, Decl.32 und $\{$ Decl.24,Decl.25\}. Keines dieser Argumente ist zwingend, jede der drei Außenseiterpositionen könnte, als Einzelerscheinung betrachtet, zur Ausnahme erklärt werden, zusammen sprechen sie aber doch gegen die Authentizität von (Decl.6), zumal andere als unecht eingestufte Werke wie [Decl.18], [Decl.29] und [Decl. 45] in den statistischen Merkmalen weniger aus dem Rahmen fallen. Hinzu kommt, daß (Decl.6) in der Klassifikation nach Funktionswörtern - wiederum zusammen mit Decl.24 und Decl.25 - am Rande der Hauptfamilie echter Deklamationen steht, in ähnlicher Position wie die Vierergruppe aus den Paaren $\{[$ Decl.34],[Decl.45]\} und $\{[$ Decl.18],[Decl.20]\}.

\section{$5.2[$ Decl.29]}

Anfang des 19. Jahrhunderts hat Friedrich Jacobs [Decl.29] als oftmals unglückliche Nachahmung von Decl.28, der ersten Parasiten-Deklamation, bezeichnet. ${ }^{171}$ Foerster schließt sich diesem Urteil im wesentlichen an, er verweist auf den Mangel an Witz, die dürftige Anlage und einige Wörter und Ausdrucksweisen, die er dem Libanios abspricht. ${ }^{172}$ Die fraglichen Wörter - mit ihren Belegautoren aus

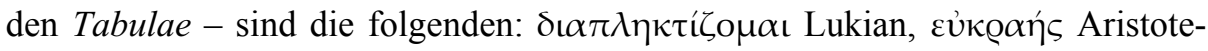

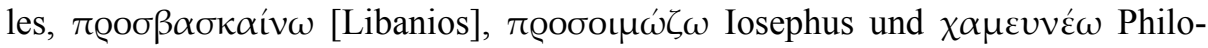
strat. Alle diese Wörter kommen im Corpus Libanianum nur einmal vor. Daß

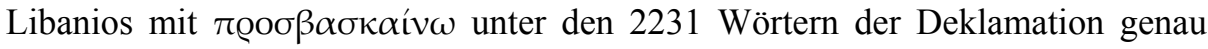
einen Erstbeleg bietet, fällt, wie wir gesehen haben, nicht aus dem Rahmen. Unter den übrigen Belegautoren könnte allenfalls Iosephus problematisch erscheinen, doch tritt Iosephus auch in den anerkanntermaßen echten Werken gelegentlich als Belegautor auf. ${ }^{173}$ Schließlich bieten auch die beiden monierten Ausdruckswei-

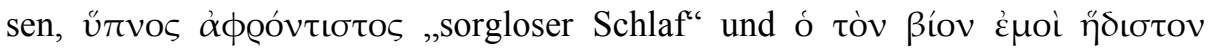
$\varepsilon \dot{\pi} \iota \delta \varepsilon \iota \kappa v v ́ \varsigma$, ,er, der mir das Leben als sehr angenehm erwiesen hat", eigentlich keinen sonderlichen Anstoß. Damit bleibt der im Vergleich zu Decl.28 unbefriedigende Gesamteindruck das einzige Argument Foersters gegen die Echtheit. Von statistischer Seite kommen ebenfalls eher schwache Argumente hinzu.

171 F. Jacobs, Lectiones, Manuskript von 1812/13, 98. Foerster hat das Manuskript aus Genfer Privatbesitz zur Verfügung gestellt bekommen, vgl. Libanius I, 77.

172 Libanius VI, 589, Anm. 2: „Nam arte priori (scil. declamationi) multum cedit, quin etiam penuriam facetiarum et exile genus tractandi non minus quam copiam vocum vel locutionum a Libanio alienarum (...) causas gravissimas praebere existimo de authentia declamationis dubitandi.“

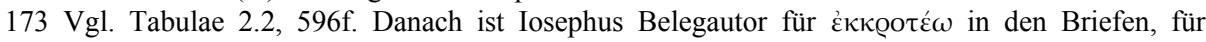

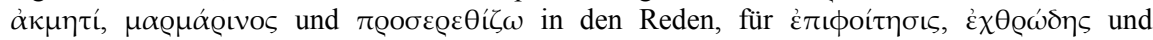

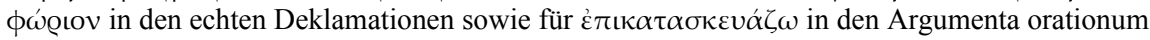
Demosthenicarum. 
Zwar hat [Decl.29] mit 9\% den weitaus geringsten Anteil an Fragen, ${ }^{174}$ dies ist aber leicht erklärbar. Der Sprecher der Deklamation ist ein Parasit, der einem luxuriösen Leben entsagen muß, weil sein Gönner sich plötzlich der Philosophie und einer strengen, kargen Lebensweise zugewandt hat. Da er sich selber zwar als gesellig, anteilnehmend und friedfertig sieht, andererseits aber als von Natur aus träge, lernschwach und ungeeignet, Mühen auf sich zu nehmen, ${ }^{175}$ bittet er nun den Stadtrat um den Schierlingsbecher. Es könnte für Libanios durchaus verlokkend gewesen sein, den Charaktertyp des kraftlosen Schlemmers in der Sprechund Argumentationsweise des Parasiten vorzuführen. Der Parasit malt noch unterhaltsam wie früher - die schöne Vergangenheit aus, aber er hat resigniert. Rhetorische Fragen passen nicht gut zu solcher Resignation, sie enthalten ein aktives, zupackendes Element und beinhalten eine verschärfte Form der Argumentation.

[Decl.29] nimmt nun auch in den Klassifikationen nach Funktionswörtern und Wortarten Außenseiterpositionen ein. Im Falle der Wortarten kann dies, wie die Residuen zeigen, ${ }^{176}$ auf einen sehr hohen Adjektivanteil zurückgeführt werden, und zwar vor allem auf einige Adjektive, die in den Tabellen der Funktionswörter und der allgemeineren Inhaltswörter für [Decl.29] hohe Residuen aufwei-

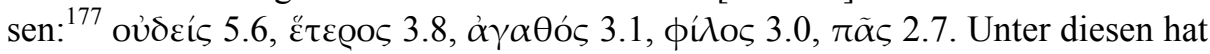

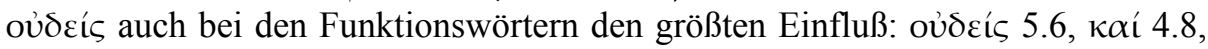

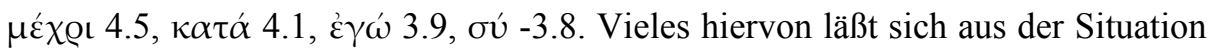
des Sprechers und aus seiner Charakterisierung durch den Verfasser der Deklamation erklären: Die Häufigkeit von $\dot{\varepsilon} \gamma \omega \dot{\omega}$, fast spiegelbildlich zur Seltenheit von $\sigma \dot{v}$, läßt eine gewisse Egozentrik erkennen, $\grave{\alpha} \gamma \alpha \theta$ ó $\varsigma$ im Neutrum Plural - den Blick auf materielle Güter, фílos den Gedanken an mögliche Helfer, die ihm am Ende

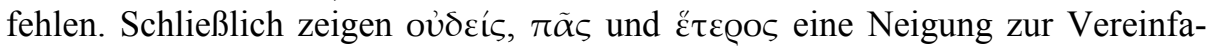
chung und eine etwas ermüdende Einförmigkeit im Denken und Sprechen des Parasiten - oder eben doch des Verfassers.

Wenn eine Deklamation nicht von Libanios stammt, so muß sich das zwar nicht notwendig in den hier untersuchten Merkmalen niederschlagen, da diese Merkmale aber ziemlich zahlreich und ziemlich unabhängig voneinander sind, sollte man meistens doch mehr oder weniger deutliche Spuren erwarten dürfen, wie sie in den bisher besprochenen Deklamationen immer wieder festzustellen waren. Da die Spuren in [Decl.29] ziemlich vage und unbestimmt erscheinen, wird man sich fragen müssen, ob dieses Werk nicht doch von Libanios stammen

174 Vor Decl.3 mit 14\%, [Decl.18] mit 15\% und [Decl.20] mit 16\%.

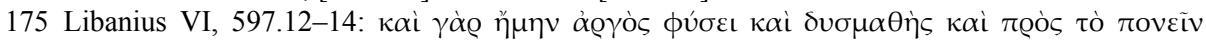

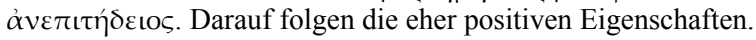

176 Tabulae 2.1, 347.

177 Tabulae 2.1, 299f. und 326f. 
könnte und ob der Eindruck der Mittelmäßigkeit, den Foerster anführt, nicht mit der Absicht des Libanios erklärt werden kann, den Sprecher eben in seinem Sprechen als schwachen und dürftigen Charakter erscheinen zu lassen. ${ }^{178} \mathrm{Im}$ übrigen hat die Deklamation durchaus ihren Reiz, und mancher Leser wird sich hier und da ein Schmunzeln nicht verkneifen können. Bedenklich stimmt allerdings $\eta \mu \eta v$ als 1. Person Singular Imperfekt von cijuí. ${ }^{179}$

\section{$5.3[$ Decl.49]}

Hermann von Rohden hat [Decl.49] aufgrund der strengen Hiatvermeidung der Rhetorenschule von Gaza zuschreiben wollen, ${ }^{180}$ Paul Maas hat sie aufgrund akzentuierender Klauseln ebenfalls dem Libanios abgesprochen. ${ }^{181}$ Foerster hält zwar diese Argumente für unzureichend, fügt aber weitere hinzu und spricht sich schließlich doch gegen die Echtheit der Deklamation aus: ${ }^{182}$ „Nam loco gratiae illius (scil. Libanii) atque simplicitatis Libanianae regnat in ea verbositas quae repetitionibus paene non sibi satisfacere posse videtur. Accedit copia formarum ..., vocabulorum ..., locutionum ... ab usu Libanii abhorrentium, vix ut declamationem genuinam habere possim." Die von Foerster monierten Wörter und ihre Belegautoren nach den Tabulae sind diese: $\alpha \lambda v \sigma \iota \tau \varepsilon \lambda \eta ́ s$ Xenophon, Platon, Isokrates und Demosthenes, $\dot{\alpha} \pi \alpha v \theta \varrho \omega \pi i ́ \alpha$ Hippokrates, $\alpha \dot{\alpha} \pi \kappa \lambda \eta \varrho o ́ v o \mu \circ \varsigma$ Arrian,

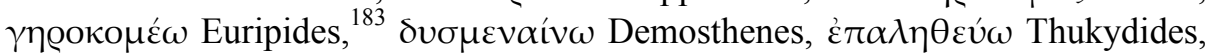

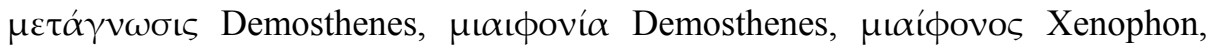

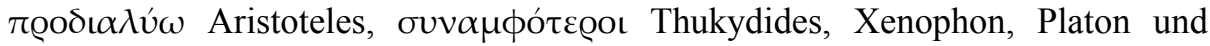
Demosthenes. Allenfalls Arrian könnte in dieser Liste problematisch erscheinen, denn er tritt als Belegautor nur noch ein weiteres Mal auf, nämlich für

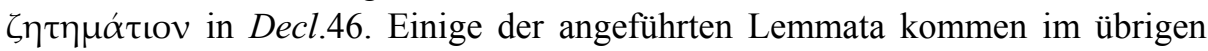

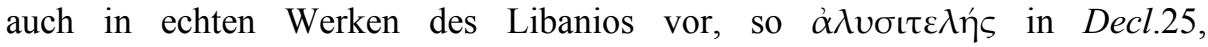

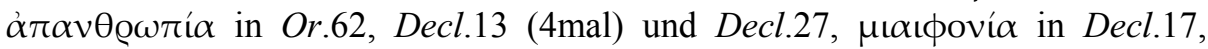

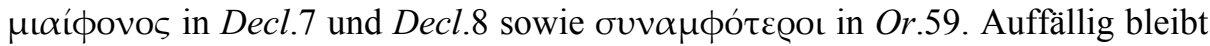

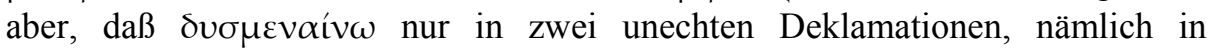

$178 \mathrm{Da}$ das Parasiten-Thema auch anders behandelt werden konnte, zeigt Decl.28.

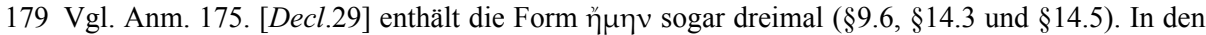
echten Briefen und Reden des Libanios tritt $\eta \mu \eta v$ nicht auf, in den Deklamationen noch zweimal in [Decl.49] (\$34.2 und §82.4) sowie je einmal in Decl.12 (§11.7) und Decl.28 (§6.5). Auch die beiden letztgenannten Werke sind nicht ganz frei von Zweifeln. Die Form $\tilde{\eta} \varsigma$ statt $\tilde{\eta} \sigma \theta \alpha$ kommt nur dreimal vor: [Decl.18] §30.8, [Decl.34] §13.6 und [Decl.49] §86.1.

180 H. v. Rohden (s. Anm. 46).

181 P. Maas (s. Anm. 47).

182 Libanius VII, 640f.

183 Ergänzen könnte man hier $\gamma$ ฤøoкó $\mu о \varsigma$ Iosephus. 


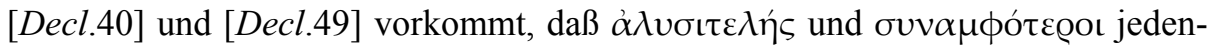
falls überwiegend in unechten oder angezweifelten Werken anzutreffen sind und

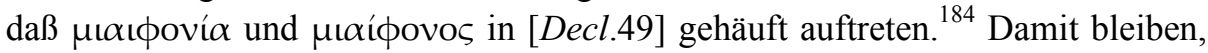
was das Vokabular betrifft, nur recht vage Verdachtsmomente bestehen. Als auffällige Wortform führt Foerster nur ein $\tilde{\eta} \varsigma$ für $\tilde{\eta} \sigma \theta \alpha$ an, als auffällige Redewen-

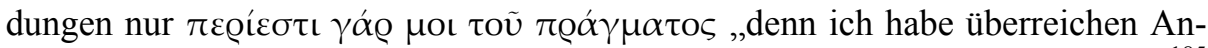

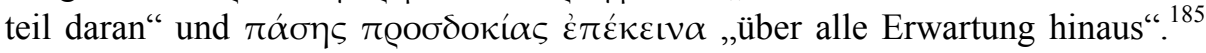

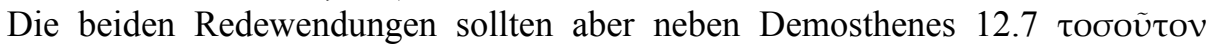

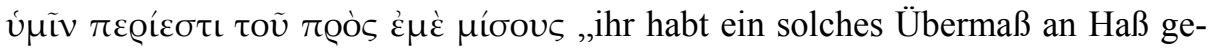

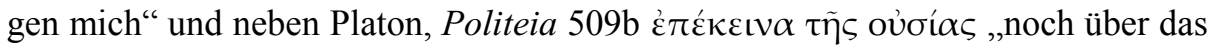

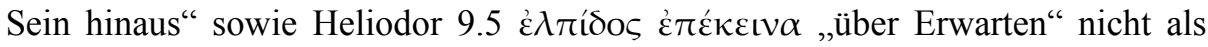
sprachliche Anstöße gesehen werden. Foersters Argumente reduzieren sich also fast ganz auf sein negatives Gesamturteil. Dieses indes, insbesondere in Puncto verbositas, wird durch die Statistik bestätigt: Das erwähnte Übermaß an Wiederholungen führt dazu, daß [Decl.49] das ärmste Vokabular aller Deklamationen hat.

Auch die anderen statistisch erfaßten Merkmale zeigen [Decl.49] vielfach in Extrempositionen. Die mittlere Wortlänge ist mit Abstand die größte im Deklamationskorpus, und die Hiatrate gehört zu den geringsten, wobei besonders die extrem strenge Hiatvermeidung an Satzeinschnitten und Satzenden auffällt. In der Verwendung der Funktionswörter weist [Decl.49] mit Abstand die meisten Einzelabweichungen extremer Signifikanz sowie die größte Gesamtabweichung vom Korpusdurchschnitt auf, und in der automatischen Klassifikation nach Funktionswörtern bleibt [Decl.49] besonders isoliert. Die extrem signifikante Häufigkeit von $\kappa \alpha \tau \alpha ́$, überboten nur in [Decl.45], stellt [Decl.49] an die Seite ganz überwiegend unechter Werke. Auch in der Verwendung der allgemeineren Inhaltswörter steht [Decl.49] äußerst isoliert. In der Buchstabenverteilung weist [Decl.49] die zweitgrößte Gesamtabweichung vom Korpusdurchschnitt auf, bei der Klassifikation nach den Buchstabenverteilungen steht das Werk sogar abseits vom gesamten Rest der Deklamationen. Bei dieser Fülle starker statistischer Indizien kann man nur folgern, daß [Decl.49] vor allen anderen Deklamationen dem Libanios abzusprechen ist.

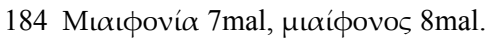

185 Libanius VII, 694.16, 667.13 und 669.1. 


\section{Zusammenfassung}

Die bisherigen Beobachtungen sollen nun zunächst in einer tabellarischen Übersicht zusammengefaßt werden:

\begin{tabular}{|c|c|c|c|c|c|c|c|c|c|c|c|c|c|c|c|c|}
\hline & \multicolumn{7}{|c|}{ Eindimensionale Skalierungen } & \multicolumn{4}{|c|}{ Gesamtabweichungen } & \multicolumn{4}{|c|}{$\begin{array}{l}\text { Außenseiterpositionen } \\
\text { im Dendrogramm }\end{array}$} & \\
\hline & $\mathrm{Vu}$ & $\mathrm{W} 1$ & $\% \mathrm{H}$ & $\mathrm{Sl}$ & $\mathrm{Fl}$ & $\% \mathrm{~F}$ & $\%{ }_{00}$ & $\mathrm{Fu}$ & $\mathrm{aI}$ & $\mathrm{Wa}$ & $\mathrm{Bu}$ & $\mathrm{Fu}$ & $\mathrm{aI}$ & $\mathrm{Wa}$ & $\mathrm{Bu}$ & $\overline{\mathrm{AU}}$ \\
\hline Decl.1 & - & - & - & - & - & - & - & $(\mathrm{X})$ & - & - & - & $=$ & - & - & - & - \\
\hline Decl.2 & - & - & - & - & - & - & - & - & - & $\mathrm{X}$ & $\mathrm{x}$ & $\mathrm{X}$ & $\mathrm{X}$ & $=$ & $=$ & $\mathrm{X}$ \\
\hline Decl.3 & - & - & - & - & - & $\mathrm{x}$ & - & - & - & - & - & - & - & - & - & - \\
\hline Decl.4 & - & - & - & - & - & - & - & $\mathrm{x}$ & - & - & - & - & - & - & - & - \\
\hline$($ Decl.6) & $\mathrm{X!}$ & - & $(\mathrm{X})$ & - & - & - & - & - & $\mathrm{x}$ & - & - & $\mathrm{x}$ & $=$ & - & - & - \\
\hline Decl.12 & - & - & - & - & $\mathrm{x}$ & - & - & $\mathrm{x}$ & $(\mathrm{X} !)$ & $\mathrm{x}$ & $\mathrm{X}$ & $=$ & $=$ & $=$ & - & - \\
\hline \begin{tabular}{|l|} 
Decl.13 \\
\end{tabular} & - & - & - & - & - & - & - & (X) & $(\mathrm{X})$ & - & $\mathrm{x}$ & $=$ & $=$ & - & $=$ & - \\
\hline$($ Decl.15) & - & - & - & - & - & - & - & - & $\mathrm{X}$ & - & $\mathrm{X}$ & $\mathrm{X}$ & $=$ & $\mathrm{X}$ & $=$ & - \\
\hline (Decl.16) & - & - & - & - & - & - & - & $X$ & $\mathrm{x}$ & - & $\mathrm{X}$ & $=$ & $=$ & $\mathrm{X}$ & $=$ & - \\
\hline [Decl.18] & - & $X$ & - & - & - & $\mathrm{x}$ & - & - & - & - & - & $\mathrm{x}$ & - & $\mathrm{x}$ & - & $\mathrm{X}$ \\
\hline Decl.19 & - & - & - & - & - & - & - & - & - & - & - & - & - & $\mathrm{X}$ & - & - \\
\hline \begin{tabular}{|l|}
{$[$ Decl.20] } \\
\end{tabular} & - & $\mathrm{X}$ & - & $\mathrm{x}$ & - & $\mathrm{x}$ & - & $\mathrm{X}$ & - & $\mathrm{X}$ & - & $=$ & - & $=$ & $\mathrm{x}$ & - \\
\hline [Decl.23] & - & - & - & - & $\mathrm{X}$ & - & - & $X$ & $\mathrm{X}$ & $\mathrm{X} !$ & $\mathrm{X}$ & $=$ & $=$ & $=$ & $=$ & - \\
\hline Decl.24 & - & $\mathrm{x}$ & $(\mathrm{X} !)$ & - & - & - & - & - & - & - & - & - & - & $\mathrm{x}$ & - & - \\
\hline Decl.25 & - & $\mathrm{X}$ & $(\mathrm{X})$ & - & - & $x$ & - & - & - & - & - & - & - & $\mathrm{x}$ & $\mathrm{x}$ & - \\
\hline Decl.26 & - & - & - & - & $\mathrm{x}$ & - & - & - & - & - & - & - & - & - & - & - \\
\hline \begin{tabular}{|l|} 
Decl.28 \\
\end{tabular} & - & - & $\mathrm{x}$ & - & - & - & $X$ & - & - & - & - & - & - & - & - & - \\
\hline \begin{tabular}{|l|} 
Decl.29] \\
\end{tabular} & - & - & - & - & - & $(\mathrm{X})$ & - & - & - & - & - & $(\mathrm{X})$ & - & $\mathrm{x}$ & - & - \\
\hline Decl.30 & - & - & - & $\mathrm{x}$ & - & - & - & - & - & - & - & - & - & - & - & - \\
\hline Decl.32 & - & - & - & - & - & - & - & - & $(\mathrm{X})$ & - & - & - & $=$ & - & - & - \\
\hline \begin{tabular}{|l|} 
Decl.34] \\
\end{tabular} & - & - & - & $\mathrm{X}$ & $\mathrm{x}$ & - & - & $X$ & $\mathrm{X}$ & - & - & $=$ & $=$ & - & - & - \\
\hline Decl.37 & - & - & - & $\mathrm{X}$ & - & - & - & - & - & - & - & $(\mathrm{X})$ & - & $\mathrm{x}$ & - & - \\
\hline Decl.38 & $\mathrm{x}$ & - & - & - & - & - & - & - & - & - & - & - & - & - & - & - \\
\hline$[$ Decl.40] & $\mathrm{X}$ & - & $\mathrm{X}$ & $\mathrm{X!}$ & - & - & $\mathrm{X}$ & - & $\mathrm{X!}$ & - & $\mathrm{X}$ & $\mathrm{X}$ & $=$ & $\mathrm{X}$ & $=$ & - \\
\hline$[$ Decl.43] & $\mathrm{x}$ & - & $\mathrm{x}$ & $\mathrm{X}$ & - & - & $\mathrm{X!}$ & $\mathrm{X}$ & - & - & $\mathrm{X}$ & $=$ & $\mathrm{X}$ & $\mathrm{x}$ & $=$ & - \\
\hline Decl.44 & $\mathrm{x}$ & - & - & - & - & - & - & - & - & - & - & - & - & - & - & - \\
\hline \begin{tabular}{|l|} 
Decl.45] \\
\end{tabular} & - & - & - & - & - & - & - & - & $\mathrm{X}$ & - & - & $\mathrm{x}$ & $=$ & - & - & - \\
\hline Decl.47 & $\mathrm{x}$ & - & - & - & - & - & - & - & - & - & - & - & - & - & - & - \\
\hline \begin{tabular}{|l|l|l} 
Decl.49] \\
\end{tabular} & $\mathrm{X} !$ & $\mathrm{X} !$ & $\mathrm{X}$ & - & - & - & - & $\mathrm{X} !$ & $\mathrm{X}$ & - & $\mathrm{X}$ & $=$ & $=$ & $\mathrm{x}$ & $=$ & - \\
\hline$[$ Decl.51] & - & - & $\mathrm{X}$ & - & - & - & $\mathrm{X}$ & - & - & - & - & - & - & - & - & - \\
\hline
\end{tabular}

Tabelle 3: Übersicht über auffällige Positionen. ${ }^{186}$

Die Abkürzungen in der Kopfzeile der Tabelle sind wie folgt aufzulösen: „Vu“ Vokabularumfang, „Wl“ Wortlänge, „\%H“ Hiatrate, „Sl“ Satzlänge, „Fl“ Fragen-

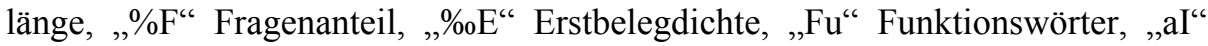
allgemeinere Inhaltswörter, „Wa“ Wortarten, „Bu“ Buchstaben, „AU“ Anlage-

186 Die in dieser Tabelle nicht enthaltenen Deklamationen bleiben unauffällig und haben aus statistischer Sicht als authentisch zu gelten. 
rung an eine unechte Deklamation. „Fu“, ,aI“, „Wa“ und „Bu“ sind zweimal vertreten, einmal für die (als z-Wert gemessene) Gesamtabweichung der betreffenden Verteilung vom Korpusdurchschnitt und einmal für Außenseiterpositionen in den betreffenden Dendrogrammen. Das ist nötig, weil manchmal auch ohne sonderlich auffällige Gesamtabweichungen Außenseiterpositionen in den Dendrogrammen eingenommen werden. ${ }^{187}$ Andererseits führen große Gesamtabweichungen fast automatisch zu solchen Außenseiterpositionen. In diesen Fällen liefern die Dendrogramme so gut wie keine Information, die nicht schon in den Angaben zur Gesamtabweichung enthalten wäre. Solche Fälle sind daher in der Tabelle durch Gleichheitszeichen markiert, eben um darauf hinzuweisen, daß zwar eine Außenseiterposition vorliegt, daß dieser Umstand aber im wesentlichen der Angabe zur Gesamtabweichung entspricht. Im übrigen sind alle auffälligen Positionen durch $\mathrm{X}$ oder $\mathrm{x}$ bezeichnet, durch großes $\mathrm{X}$, wenn es sich um Extrempositionen in der Umgebung fast ausschließlich unechter Werke handelt, durch kleines $\mathrm{x}$, wenn weniger extreme Positionen vorliegen, die unter Umständen auch einem Übergangsbereich zu den echten Werken angehören können. Dem großen X ist ein Ausrufezeichen beigegeben, wenn eine Extremposition deutlich herausragt. Eingeklammert sind $\mathrm{X}$ ! oder $\mathrm{X}$, wenn die betreffenden Besonderheiten relativ leicht erklärbar erscheinen.

Diejenigen Deklamationen, die in der Tabelle nur ein einziges $\mathrm{X}$ oder $\mathrm{x}$ aufwiesen, die also in genau einem der hier erfaßten Merkmale auffallen, sind nach Foerster/Münscher alle echt: Decl.1, Decl.3, Decl.4, Decl.19, Decl.26, Decl.30, Decl.32, Decl.38, Decl.44 und Decl.47. Umgekehrt gelten alle Deklamationen, die in sechs oder mehr Merkmalen auffallen, nach Foerster/Münscher als unecht: [Decl.20], [Decl.40], [Decl.43] und [Decl.49]. Soweit stimmen also die statistischen Ergebnisse völlig mit der traditionellen Bewertung überein. Das gilt ähnlich auch noch für die Deklamationen mit vier auffälligen Positionen, sie gelten nach Foerster/Münscher als zweifelhaft, in einem Fall sogar als unecht: (Decl.6), (Decl.15), (Decl.16) und [Decl.34]. Die statistischen Ergebnisse sprechen hier eher gegen die Authentizität. ${ }^{188} \mathrm{~A}$ fortiori sollten nun, jedenfalls aus statistischer Sicht, die Deklamationen mit fünf auffälligen Positionen als ziemlich zweifelhaft bis unecht gelten: Decl.2, Decl.12, [Decl.18], [Decl.23] und Decl.25. Man sieht, daß unsere Statistik sowohl Foersters alte Zweifel an der Authentizität von Decl.2 als auch die Bedenken von P. Maas und H. v. Rohden gegenüber Decl.25 erheblich stärkt. Außerdem muß aber offenbar die Authentizität von Decl.12 als ziemlich zweifelhaft angesehen werden, auch wenn die Besonderheiten im Gebrauch

187 Das beste Beispiel sind (Decl.15) und (Decl.16) bei den Wortarten.

188 Bei (Decl.6) in etwas geringerem Grade. 
der allgemeineren Inhaltswörter dort mit dem Inhalt erklärt werden können. ${ }^{189}$ Die Deklamationen mit zwei oder drei auffälligen Positionen sollten nach den Ergebnissen dieser Übersicht einem Übergangsbereich zwischen echten und zweifelhaften bzw. unechten Werken angehören, und tatsächlich mischen sich in diesem Bereich echte und unechte Deklamationen.

Insgesamt liefert die Disposition der Deklamationen nach der bloßen Anzahl auffälliger Positionen folgende Gruppen:

1: Decl.1, Decl.3, Decl.4, Decl.19, Decl.26, Decl.30, Decl.32, Decl.38, Decl.44, Decl.47.

2: Decl.28, [Decl.45], [Decl.51]..$^{190}$

3: Decl.13, Decl.24, [Decl.29], Decl.37.

4: (Decl.6), (Decl.15), (Decl.16), [Decl.34].

5: Decl.2, Decl.12, [Decl.18], [Decl.23], Decl.25.

6: [Decl.20].

7: [Decl.49].

8: [Decl.40], [Decl.43].

Die Berücksichtigung nur der Anzahl auffälliger Positionen bedeutet, daß alle X!, $\mathrm{X}$ und $\mathrm{x}$ mit dem Wert 1.0 gezählt werden. Es scheint aber besser, besonders im Hinblick auf eine sinnvolle Gruppenbildung, hier weiter zu differenzieren und X! mit 1.33 sowie kleines x mit $0.66 \mathrm{zu}$ bewerten. ${ }^{191}$ Das führt, wenn alle möglichen Summen von 0.66 bis 8.33 aufgelistet werden, zu folgender Gruppierung:

0.66: Decl.3, Decl.4, Decl.19, Decl.26, Decl.30, Decl.38, Decl.44, Decl.47.

1.00: Decl.1, Decl.32.

1.33:-

1.66: Decl.28, [Decl.45], [Decl.51].

2.00: -

2.33:-

2.66: Decl.13, Decl.24, [Decl.29], Decl.37.

3.00: -

189 Wobei noch anzumerken ist, daß Decl.12 und [Decl.45] auch für die mittlere Wortlänge ein $\mathrm{x}$ hätten erhalten können.

190 Decl.28 und [Decl.51] fallen beide durch eine niedrige Hiatrate und eine hohe Erstbelegdichte auf, wobei besonders die Erstbelegdichte in Decl.28 zu Buche schlägt. Den hier untersuchten Merkmalen zufolge müßte also - was aber auch von der Einschätzung der Merkmale abhängt eher Decl.28 als [Decl.51] in der Authentizität angezweifelt werden.

191 Versuchsweise habe ich auch mit $1 \frac{1}{2}$ für X! und $1 / 2$ für $\mathrm{x}$ gearbeitet, mit fast identischem Ergebnis. Doch erscheint mir eine Differenzierung um $\pm 1 / 2$ im ganzen zu stark. 
3.33:-

3.66: (Decl.6), (Decl.16), [Decl.34].

4.00: (Decl.15), [Decl.18], Decl.25.

4.33: Decl.12.

4.66: Decl.2.

5.00: [Decl.20].

5.33: [Decl.23].

5.66: -

6.00:-

6.33:-

6.66: -

7.00: -

7.33: [Decl.43].

7.66: [Decl.49].

8.00: -

8.33: [Decl.40].

In dieser Darstellung sind die Deklamationsgruppen durch unbesetzte Bereiche deutlicher voneinander getrennt, und die zugrundeliegende Bewertung entspricht einer weniger starken Vereinfachung als bei bloßer Zählung auffälliger Positionen. Dennoch stimmen beide Listen weitgehend überein, besonders am Anfang (1 bis 3 auffällige Positionen) und am Ende ( 7 oder 8 auffällige Positionen), aber auch im mittleren Bereich sind die Verschiebungen gering. Es ergeben sich so, mit einer vorläufigen Einschätzung der Echtheitsfrage allein aus statistischer Sicht, folgende Gruppen:

1) authentisch: Decl.3, Decl.4, Decl.19, Decl.26, Decl.30, Decl.38, Decl.44 und Decl.47 sowie Decl.1 und Decl.32.

2) vielleicht authentisch, aber nicht ganz frei von Zweifeln, dabei nicht stark von der ersten Gruppe abgehoben: Decl.28, [Decl.45], [Decl.51].

3) zweifelhaft: Decl.13, Decl.24, [Decl.29], Decl.37.

4) sehr zweifelhaft bis nicht authentisch: (Decl.6), (Decl.16), [Decl.34], (Decl.15), [Decl.18], Decl.25, Decl.12, Decl.2, [Decl.20], [Decl.23].

5) nicht authentisch: [Decl.43], [Decl.49], [Decl.40].

Diese Einschätzung muß allerdings in zwei Punkten revidiert werden. Erstens muß [Decl.45] aufgrund der von Foerster bzw. Foerster/Münscher angeführten Einzelbeobachtungen als unecht gelten und von der zweiten in die vierte Gruppe gestellt werden. Dies ist im übrigen der einzige Fall, in dem Gründe, die die hier untersuchten Merkmale nicht berühren, zu einer veränderten Einschätzung führen. 
Daher ist es auch eher unwahrscheinlich, daß weitere Umstellungen nötig würden, wenn zusätzliche Merkmale herangezogen werden könnten. ${ }^{192}$

Zweitens muß erwogen werden, ob und in welchem Umfang die eingeklammerten X-Positionen überhaupt mitzuzählen sind. Dazu ist zunächst zu bemerken, daß ich die Klammern in der Regel nur dort gesetzt habe, ja der Frage nach der Erklärbarkeit bestimmter Besonderheiten überhaupt nur dort nachgegangen bin, wo möglicherweise ein Urteil über die Authentizität berührt schien. Damit ist schon die Problematik dieser Klammerungen angedeutet: Letztlich müssen alle Besonderheiten irgendwie erklärbar sein, und eine Relativierung aller auffälligen Positionen würde der vorliegenden Untersuchung, die ja in ihren Hauptergebnissen gut mit den Urteilen von Foerster/Münscher übereinstimmt, die Grundlage entziehen. In diesem Punkt ist große Vorsicht und Zurückhaltung angezeigt, wobei es vor allem auf das Wie der Erklärbarkeit ankommt. Prinzipiell stellt sich die Frage, ob (a) thematischer Zwang vorliegt, ob (b) die Anlage einer Deklamation fast automatisch zu einer Besonderheit führt, ob (c) Besonderheiten in der Art der Bearbeitung und Ausführung mit besonderen Bedingungen (z.B. Jugendalter) oder Darstellungsabsichten (z.B. Ethopoeie) innerhalb eines breiten Spektrums bei Libanios selbst erklärt werden können, oder ob (d) die Autorschaft anzuzweifeln ist. Zu allermeist nun scheinen auffällige Positionen, jedenfalls im Vergleich mit der Einschätzung bei Foerster/Münscher, auf Fall (d) zu deuten. Das heißt aber nicht, daß nicht einzelne Ausnahmen in den anderen Fällen zugelassen werden könnten. Am deutlichsten ist wohl der Einfluß thematischen Zwangs auf all-

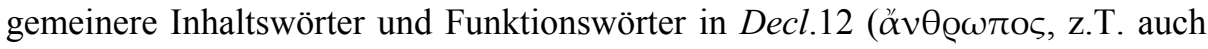

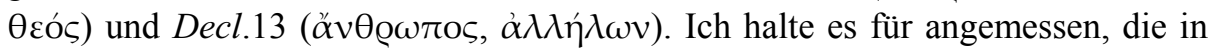
den obigen Listen angegebenen Punktesummen für diese beiden Deklamationen um 1.0 (oder auch 1.3) zu reduzieren. Damit rückt Decl.13 von der 3. Gruppe (zweifelhaft) in die 2. auf (vielleicht authentisch), und Decl.12 kommt auf eine Position zwischen der 3. und 4. Gruppe, die als ,ziemlich zweifelhaft“ bezeichnet werden könnte, die aber, da Decl.12 auch ein x für die Wortlänge hätte erhalten können, mehr zur 4. Gruppe tendiert. Ohne Einfluß auf die Echtheitsfrage bliebe eine Reduzierung bei Decl.1, Decl.32 und, wie sich noch zeigen wird, bei Decl.37. In Decl.32 erklärt zwar der Inhalt die Häufigkeit bestimmter allgemeinerer Inhaltswörter, ein wirklicher thematischer Zwang scheint mir aber nicht vorzuliegen. In Decl.1 ist die Seltenheit der Pronomina der ersten Person durch die Anlage der Deklamation bedingt (Sokrates verteidigt sich nicht selbst), ebenso

192 Ein solches Merkmal könnte z.B. der Anteil der Partizipien unter den Verbformen sein. Besonders interessant wäre ein Index für die rhetorische Dichte, wie ihn Rother für die Reden des Libanios geliefert hat, vgl. C. Rother, De Libanii arte rhetorica quaestiones selectae, Diss. Breslau, Liegnitz 1915, 104-106. Dazu P. Petit, Recherches sur la publication et la diffusion des discours de Libanios, in: Historia 5 (1956) 479-509. 
wie ihre Häufigkeit in Decl.37. Da aber die Anlage einer Deklamation im Belieben des Autors steht, ja seiner Absicht entspricht, ist auch hier keine Zwangslage im strengen Sinne anzunehmen, die eine Reduzierung der Punktesummen nahelegen würde. Es zeigt sich hier nichts anderes, als daß auch echte Deklamationen gelegentlich auffällige Positionen einnehmen können und daß vereinzelte Auffälligkeiten eben zum Stil des Libanios gehören. Von vornherein ambivalent ist die Seltenheit rhetorischer Fragen und die Häufigkeit bestimmter Funktionswörter in [Decl.29]: Beides kann im Sinne besonderer Darstellungsabsicht wie auch als Hinweis auf fremde Autorschaft gedeutet werden. Da aber die Form $\eta \mu \eta v$ gegen Libanios als Autor spricht, erübrigt sich die Annahme gezielter Ethopoeie und damit auch die Annahme von mehr als zwei Ausnahmen in ein und derselben Deklamation. Eine Reduzierung der Punktesumme für [Decl.29] erschiene ziemlich willkürlich. Damit sind - bis auf die Fälle strenger Hiatvermeidung - alle zu erwägenden Revisionen besprochen. Festzuhalten ist, daß nur in zwei Fällen thematischen Zwangs, bei Decl.12 und Decl.13, eine Reduzierung des statistischen Befunds angeraten erscheint.

Was den Hiat betrifft, so stellt sich vordergründig die Frage, ob man annehmen kann, daß Libanios eine strenge Hiatvermeidung selektiv und gezielt zur Charakterdarstellung eingesetzt hat. ${ }^{193}$ Betroffen wären vor allem drei Deklamationen mit peloponnesischen Sprechern, (Decl.6), Decl.24 und Decl.25. ${ }^{194}$ Aber auch Decl.28 und [Decl.51] haben auffallend niedrige Hiatraten, und zwar ohne daß eine besondere Motivation erkennbar wäre. Jedenfalls unterliegt die Hiatrate keinem äußeren Zwang, vielmehr ist sie als stilistisches Element aufzufassen, dessen Gestaltung in der Hand des Autors liegt. Sie sollte daher ebenso behandelt werden wie die anderen Merkmale dieser Art: Auffällige Positionen, wie immer auch vielleicht erklärbar, sind bei Libanios in seltenen Fällen zuzulassen, im Zusammentreffen mit anderen Sonderstellungen verstärken sie aber die Zweifel an seiner Autorschaft. Es wäre inkonsequent und willkürlich, die eingeklammerten X-Positionen in der Hiatrate nicht mitzuzählen.

Die obigen Erörterungen zeigen, daß ich eine nachträgliche Ausklammerung auffälliger Erscheinungen dort und nur dort vorgenommen habe, wo der Autor unter echtem thematischem Zwang stand. Dem könnte entgegengehalten werden, daß auch die Anlage einer Deklamation, einmal gewählt, eine Vorgabe ist, die gewisse Zwänge ausüben kann, daß also Fall (b) nur graduell von Fall (a) unterschieden ist und beide Fälle ähnlich behandelt werden müßten. Diese Position ist durchaus vertretbar. Sie hätte zur Folge, daß entweder gar keine Reduktion vor-

193 Immerhin erwägen Foerster/Münscher, Sp. 2511, eine einigermaßen vergleichbare Möglichkeit: „Es bleibt zu untersuchen, ob es Libanios mit der Lex Meyeriana zeitweise versucht hat.“

194 Im übrigen müßte Decl.24 wegen der Paarbindung an Decl.25 ein zusätzliches x unter „AU“ erhalten, wenn man Decl.25 als unecht oder zweifelhaft ansieht. 
genommen werden dürfte, also die aus thematischem Zwang entstandenen Besonderheiten zu den normalen Ausnahmen oder Verdachtsmomenten zu zählen wären, oder daß auch die anlagebedingten Besonderheiten zu einer gewissen Reduzierung der Punktesummen führen müßten - was aber in unserem Fall nur hieße, daß zwei echte Deklamationen, Decl.1 und Decl.37, als „noch echter“ anzusehen wären. Erwägenswert bleibt daher nur die Alternative, die von mir vorgeschlagene Reduzierung bei Decl.12 und Decl.13 aufzuheben. Die Entscheidung darüber sei dem Leser überlassen, doch soll im folgenden eine statistische Überlegung skizziert werden, die als Entscheidungshilfe dienen könnte.

Nach Foerster/Münscher gelten 38 Deklamationen als echt, und unter diesen haben 10, also etwa $26 \%$, genau eine auffällige Besonderheit (X oder $\mathrm{x}) \cdot{ }^{195} \mathrm{Da} \beta$ diese 10 Deklamationen wirklich authentisch sind, unterliegt wohl keinem Zweifel. Die Wahrscheinlichkeit, daß eine Deklamation in genau zwei unabhängigen Merkmalen auffällt, kann dann durch $0.26 \cdot 0.26 \approx 0.07$ abgeschätzt werden, und unter den 38 echten Deklamationen wären ungefähr $38 \cdot 0.07=2.66$ solcher Fälle zu erwarten. Analog ergibt sich eine zu erwartende Anzahl von 0.67 echten Deklamationen mit genau drei auffälligen Positionen. ${ }^{196}$ Diesen Erwartungswerten kommt man am nächsten, wenn drei echte Deklamationen mit zwei X-Positionen und eine mit drei solchen Positionen angesetzt werden. Da aber anscheinend nicht alle der 38 ,echten“ Deklamationen wirklich authentisch sind, liegen die Erwartungswerte für authentische Deklamationen etwas tiefer: Man sollte unter den 38 „echten“ Deklamationen zwei bis drei authentische mit 2 Besonderheiten und vielleicht eine mit 3 Besonderheiten erwarten, im letzten Fall aber eher eine als keine. Demnach ist es problemlos, ja sogar angeraten, Decl.28, Decl.13 (nach Reduzierung) und Decl.37 zur Gruppe der authentischen Deklamationen zu stellen. ${ }^{197}$ Da aber Decl.28 die Form n̆ $\mu \eta v$ enthält und [Decl.51] ganz isoliert in einer späten Handschrift überliefert ist, ${ }^{198}$ ist es wohl besser, diese beiden Deklamationen nur in der Nähe der authentischen Werke anzusiedeln. ${ }^{199}$ Insgesamt ergibt sich so folgende Gruppierung:

195 Es sind Decl.1, Decl.3, Decl.4, Decl.19, Decl.26, Decl.30, Decl.32, Decl.38, Decl.44 und Decl.47.

196 Vier auffällige Positionen wären nur noch bei 0.17 echten Deklamationen zu erwarten.

197 Decl.24 steht in dieser Hinsicht zwar in Konkurrenz zu Decl.37, bleibt wegen der engen Bindung an Decl.25 aber zweifelhaft.

198 S. Anm. 179 und Libanius VII, 727f.

199 In ähnlicher Weise könnte auch Decl.37 aufgrund der von Paul Maas beobachteten akzentuierenden Klauseln (s. Anm. 47) wieder etwas von den authentischen Werken abgerückt und zu Decl.28 und [Decl.51] gestellt werden, doch hat Maas selber im Falle von Decl.27 keinen Anstoß an dieser Rhythmik genommen. 
1) authentisch: Decl.1, Decl.3, Decl.4, Decl.13, Decl.19, Decl.26, Decl.30, Decl.32, Decl.37, Decl.38, Decl.44, Decl.47.

2) vielleicht authentisch, aber nicht ganz frei von Zweifeln: Decl.28, [Decl.51].

3) zweifelhaft: Decl.24 und [Decl.29].

4) sehr zweifelhaft bis nicht authentisch: Decl.2, (Decl.6), Decl.12, (Decl.15),

(Decl.16), [Decl.18], [Decl.20], [Decl.23], Decl.25, [Decl.34], [Decl.45].

5) nicht authentisch: [Decl.40], [Decl.43], [Decl.49].

Diese Übersicht paßt ziemlich gut zu früheren Ergebnissen, hauptsächlich zu denen von Foerster/Münscher, aber auch zu denen von Paul Maas und Hermann v. Rohden. Darüber hinaus erscheint Decl.12 ziemlich zweifelhaft. Im übrigen ist mit der Aufnahme von Decl.13, Decl.28 und Decl.37 in die Gruppe der authentischen bzw. vielleicht authentischen Werke das Potential solcher Aufnahmen noch nicht ganz ausgeschöpft: Es ist angemerkt worden, daß der Erwartungswert für eine Deklamation mit genau vier auffälligen Besonderheiten ungefähr 0.17 beträgt, ein Wert, der zwar erheblich dichter bei Null als bei Eins liegt, der aber doch deutlich über Null bleibt. Gäbe es nicht 38 echte Deklamationen, sondern etwa die sechsfache Menge, so wäre tatsächlich eine mit vier X-Positionen zu erwarten, und diese könnte auch eine der ersten 38 sein. Die Wahrscheinlichkeit dafür beträgt zwar nur ein Sechstel, aber damit erscheint eine Anerkennung entweder von Decl.12 oder von Decl.24 als authentisch aus statistischer Sicht wenigstens nicht völlig abwegig. ${ }^{200}$

Anzumerken ist schließlich, daß alle statistischen Merkmale als gleichwertig behandelt worden sind, denn für eine unterschiedliche Gewichtung scheint es keine verläßliche Grundlage zu geben. Die Ergebnisse zeigen aber, daß sich diese Gleichbehandlung im vorliegenden Fall bewährt hat. ${ }^{201}$

200 Decl.12 nach Tilgung von X! unter „aI“ bzw. Decl.24 nach Ergänzung von x unter „AU“.

201 Abgekürzt zitierte Literatur: „Foerster/Münscher“ s. Anm. 1, „Tabulae“ s. Anm. 2, „Libanius“ s. Anm. 3, „Sprachstatistische Untersuchungen“" s. Anm. 18. Die Abkürzungen in der Kopfzeile von Tabelle 3 sind unmittelbar im Anschluß an die Tabelle erläutert. Außerdem sind in den Fußnoten einige Abkürzungen aus den Tabulae als Verweis auf dortige Tabellenüberschriften zitiert, etwa „Wl“, ,senl“ und ,z(Vu)“. Diese Abkürzungen sind in den Einleitungen der Tabulae erläutert, sie können aber auch in Analogie zu den Abkürzungen von Tabelle 3 erschlossen werden (z.T. über das Englische wie bei sentence length). 
